\title{
Strain-dependent effects of clinical echovirus 30 outbreak isolates at the blood-CSF barrier
}

Tobias Dahm ${ }^{1}$, Ortwin Adams², Sindy Boettcher ${ }^{3}$, Sabine Diedrich ${ }^{3}$, Vasily Morozov ${ }^{4,5}$, Grant Hansman ${ }^{4,5}$, Petra Fallier-Becker ${ }^{6}$, Sebastian Schädler ${ }^{7}$, Claus J. Burkhardt ${ }^{8}$, Christel Weiss ${ }^{9}$, Carolin Stump-Guthier ${ }^{1}$, Hiroshi Ishikawa ${ }^{10}$, Horst Schroten ${ }^{1}$, Christian Schwerk ${ }^{1}$, Tobias Tenenbaum ${ }^{1}$ and Henriette Rudolph ${ }^{1 *}$ (D)

\begin{abstract}
Background: Echovirus (E) 30 (E-30) meningitis is characterized by neuroinflammation involving immune cell pleocytosis at the protective barriers of the central nervous system (CNS). In this context, infection of the blood-cerebrospinal fluid barrier (BCSFB), which has been demonstrated to be involved in enteroviral CNS pathogenesis, may affect the tight junction (TJ) and adherens junction (AJ) function and morphology.

Methods: We used an in vitro human choroid plexus epithelial (HIBCPP) cell model to investigate the effect of three clinical outbreak strains (13-311, 13-759, and 14-397) isolated in Germany in 2013, and compared them to E-30 Bastianni. Conducting transepithelial electrical resistance (TEER), paracellular dextran flux measurement, quantitative real-time polymerase chain reaction (qPCR), western blot, and immunofluorescence analysis, we investigated TJ and AJ function and morphology as well as strain-specific E-30 infection patterns. Additionally, transmission electron and focused ion beam microscopy electron microscopy (FIB-SEM) was used to evaluate the mode of leukocyte transmigration. Genome sequencing and phylogenetic analyses were performed to discriminate potential genetic differences among the outbreak strains.
\end{abstract}

Results: We observed a significant strain-dependent decrease in TEER with strains E-30 Bastianni and 13-311, whereas paracellular dextran flux was only affected by E-30 Bastianni. Despite strong similarities among the outbreak strains in replication characteristics and particle distribution, strain 13-311 was the only outbreak isolate revealing comparable disruptive effects on TJ (Zonula Occludens (ZO) 1 and occludin) and AJ (E-cadherin) morphology to E-30 Bastianni. Notwithstanding significant junctional alterations upon E-30 infection, we observed both para- and transcellular leukocyte migration across HIBCPP cells. Complete genome sequencing revealed differences between the strains analyzed, but no explicit correlation with the observed strain-dependent effects on HIBCPP cells was possible.

Conclusion: The findings revealed distinct E-30 strain-specific effects on barrier integrity and junctional morphology. Despite E-30-induced barrier alterations leukocyte trafficking did not exclusively occur via the paracellular route.

Keywords: Enterovirus, Echovirus (E-30), Blood-cerebrospinal fluid barrier, Outbreak strains, Tight junction, Genomic sequencing, CNS, Meningitis, Transcellular transmigration, Paracellular transmigration

\footnotetext{
* Correspondence: Henriette.rudolph@medma.uni-heidelberg.de

${ }^{1}$ Pediatric Infectious Diseases, University Children's Hospital Mannheim,

Medical Faculty Mannheim, Heidelberg University, Mannheim, Germany

Full list of author information is available at the end of the article
} 


\section{Background}

Non-polio enteroviruses (NPEV) are the most common cause of viral meningitis in the developed world especially in children $[1,2]$. Epidemiological data also suggest an important impact of NPEV on populations in Africa, Asia, and South America [3-6]. Disease course can range from mild clinical presentations to severe complications such as meningitis, encephalitis, or acute flaccid paralysis [6, 7]. As a result of Enterovirus surveillance programs, and intensified molecular and genetic typing, knowledge on epidemiology and clinical courses of different serotypes and genotypes of NPEV is currently expanding [6]. However, linking genetic variations of E-30 to disease severity or frequency has not been carried out so far. Particularly, the biological mechanisms underlying virulence, fitness, and tropism of different serotypes and genotypes of NPEV are currently undefined, although this knowledge is essential for better control of outbreaks and design of targeted prevention or treatment strategies [6].

Echovirus (E) 30 (E-30), belonging to the genus of enterovirus and a member of the family Picornaviridae, is a nonenveloped, single-stranded positive-sense RNA virus with a genome of $7.5 \mathrm{~kb}$. Especially in Europe, E-30 is prevailing in patients with NPEV central nervous system (CNS) infections [8-10]. In parallel, more and more frequent epidemics with E-30 occur in Asia [11] and (South) America [12].

So far, two main routes for NPEV into the immune privileged site of the CNS $[13,14]$ have been analyzed: passage across the blood-brain barrier (BBB) [15-17] and entry across the blood-cerebrospinal fluid (CSF) barrier (BCSFB) [18-20]. At the level of the BBB, endothelial cells are firmly connected through tight junctions (TJ) and adherens junctions (AJ). In human BBB models applying human brain microvascular endothelial cells (HBMEC) or human cerebral microvascular endothelial cells (hCMEC/ D3), it was shown that infection with poliovirus [16], E-6, $\mathrm{E}-12$, and E-30 [17] resulted in damage to the junctional connections, leading to increased paracellular permeability of the barrier. In contrast to the $\mathrm{BBB}$, endothelial cells of the choroid plexus at the level of the BCSFB are fenestrated and the polar choroid plexus epithelial cells, connected through compact TJ and AJ proteins, maintain the highly selective barrier $[21,22]$. The effect of different NPEVs on the barrier function and morphology of the BCSFB has not been investigated yet. Previously, it could be demonstrated that E-30 Bastianni can infect human choroid plexus epithelial (HIBCPP) cells and lead to alteration of barrier function $[19,23]$.

Disruption of the BCSFB and BBB barrier functions may lead to influx of leukocytes into the CNS. In this context, NPEV meningitis is often accompanied by CSF pleocytosis with an early influx of polymorphonuclear (PMN) cells [24-27] followed by increasing numbers of CD4 ${ }^{+}$T-cells [28]. For the BCSFB, it was recently shown that E-30 infection resulted in an enhanced migration of PMN and T-cells in vitro [23]. Leukocyte migration across endothelium or epithelium can occur via two routes, para- and transcellular [29-34]. For transepithelial PMN migration, a dominantly paracellular approach has been observed $[35,36]$. Still, it has been noticed that transcellular diapedesis of PMN and T-cells is also a common phenomenon [37-39]. However, investigation of the leukocyte migration pathway in the context of NPEV CNS infection is currently lacking. In this study, we compared the effects of different clinical E-30 outbreak strains (13-311, 13-759, and 14-397) with E-30 Bastianni to obtain information about their in vitro virulence and tropisms within a human BCSFB model. Additionally, the pathway of leukocyte migration following infection with E-30 was analyzed.

\section{Methods \\ Cell lines}

Human choroid plexus papilloma (HIBCPP) cells [40] were cultivated on cell culture inserts and were maintained in DMEM/HAM's F12 1:1 supplemented with 10 or $1 \%$ inactivated fetal calf serum (FCS), $4 \mathrm{mM}$ L-Glutamine, streptomycin $(100 \mu \mathrm{g} / \mathrm{ml})$ and penicillin $(100 \mathrm{U} / \mathrm{ml})$, insulin $(5 \mu \mathrm{g} / \mathrm{ml})$, previously described by Dinner et al. [41]. For control experiments, the human rhabdomyosarcoma (RD) cell line was used, which is commonly used to propagate NPEV. Culture was performed in DMEM/HAM's medium containing $10 \%$ FCS on 24-well plates.

\section{Cell culture and barrier integrity evaluation}

For the purpose of a filter-based experimental set-up, HIBCPP cells were seeded on inverted culture filter inserts (Millipore and Sarsted, Germany; pore diameter $5.0 \mu \mathrm{m}$, pore density $6.0 \times 10^{5}$ pores $/ \mathrm{cm}^{2}$, area $0.33 \mathrm{~cm}^{2}$ ). The inverted cell culture system was chosen to allow physiologically relevant infection from the basolateral cell side [41, 42]. Evaluation of barrier integrity over the course of the experiment was performed through measurement of transepithelial electrical resistance (TEER) using a tissue voltohmmeter (Millipore, Germany) and permeability analysis of dextran-TexasRed (Invitrogen, Germany) tracer solution $(100 \mu \mathrm{g} / \mathrm{ml})$ following the predescribed methodology $[19,39]$. In brief, dextranTexasRed was added to the upper filter compartment after $24 \mathrm{~h}$ of infection for $4 \mathrm{~h}$ before its concentration was evaluated using a Tecan infinite M200 Multiwell reader (Tecan, Switzerland). For all experiments, barrier function was monitored through measurement of TEER and flux of TexasRed-labelled dextran over the $28 \mathrm{~h}$.

\section{Viral propagation, titration, and infection}

For this study, four different E-30 strains were used: a clinical isolate, from 1958, E-30 Bastianni (prototype strain) [43], referred to within the figures of the manuscript as 
E-30 Bast., and three E-30 outbreak strains isolated in Germany 2013 and 2014, referred to as 13-311, 13-759, and 14-397. Virus replication was measured using qPCR analysis as previously described [19]. All strains were provided by the National Reference Centre for Poliomyelitis and Enteroviruses (NRC PE) at the Robert Koch-Institute (RKI) (Berlin, Germany). Selection of inverted filter inserts with HIBCPP cell layers for experiments was based on the TEER reaching appropriate levels from 215 to $675 \Omega \times$ $\mathrm{cm}^{2}$. All experiments were performed in migration assay medium (MAM), which was not changed over the course of the experiments, and consisted of RPMI-1640 medium supplemented with 5\% FCS, HEPES (25 mM), and Glutamine (2\%). Infection was performed using a multiplicity of infection (MOI) of 0.7 added to the upper compartment of the filter insert. To identify the virus localization within the in vitro set-up, supernatant from the upper (basolateral cell side) and lower (apical cell side) filter compartment was collected at 0,5 , and $24 \mathrm{~h}$, kept separated, centrifuged at $3500 \mathrm{~g}$ for $10 \mathrm{~min}$. Supernatant was stored at $-80^{\circ} \mathrm{C}$. Additionally, filter membranes covered with a HIBCPP cell-layer were cut out using a scalpel and were stored in PBS. Repeated freeze/thaw cycles $\left(2 \times-20{ }^{\circ} \mathrm{C}\right.$ followed by $1 \times-80{ }^{\circ} \mathrm{C}$ ) followed by centrifugation at $3500 \mathrm{~g}$ for $10 \mathrm{~min}$ and collection of supernatant was performed. Further analysis via qPCR analysis applying the two-stepRNA-PCR protocol was carried out as described above. For control experiments, RD cells seeded in 48-well plates were infected with different E-30 strains at an MOI of 0.7. Collection of viral particles located in the supernatant or within the cells was performed as described above for HIBCPP cells. TaqMan qPCR analysis (see above) was performed for analysis of virus genome copies.

\section{Cell viability}

HIBCPP cell viability was analyzed through application of the live/dead assay after 28-h infection according to the manufacturer's instructions (Invitrogen, Germany). In principle, calcein green penetrates the cell membrane and in combination with esterase in the cytoplasm elicits a green fluorescent signal. In contrast, the red fluorescent ethidium homodimer is unable to enter healthy cells; however, penetration and DNA intercalation of damaged cell membranes are possible. The emitted fluorescent signal was analyzed under a fluorescent microscope, and two-dimensional images were recorded. Images were taken with a Zeiss Apotome and ZEN software (Carl Zeiss, Germany) using a $\times 20 / 1.4$ objective lens. In order to verify virulence of E-30 strains after passage across the HIBCPP cells, infection of RD cell monolayers with the supernatant from uninfected and infected HIBCPP cells was performed. Cytopathic effect was observed via light microscopy.

\section{Measurement of lactate dehydrogenase (LDH) activity} Cellular integrity up to $28 \mathrm{~h}$ post infection was evaluated through measurement of the lactate dehydrogenase concentration in the HIBCPP cell supernatant through application of a commercially available kit (Roche, Germany). Supernatant of uninfected unlysed HIBCPP was used as negative control, and lysed HIBCPP cells (enabling maximum LDH release) were used as a positive control. Both values were used to calculate the percentage of LDH activity after enteroviral infection.

\section{Immunofluorescence analysis of tight and adherens junction proteins and immune cell migration}

In principle, analysis of immunocytochemistry was performed as previously described for primary porcine choroid plexus epithelial cells (PCPEC) and HIBCPP cells [42, 44]. Filter membranes were washed and fixed with $4 \%$ formaldehyde $(w / v$ in PBS) for $10 \mathrm{~min}$ at room temperature (RT). Permeability of the membrane was ensured through incubation in $0.5 \%$ Triton X-100/ $1 \%$ bovine serum albumin (BSA) $(v / v$ in PBS) for 20 min at RT. Staining was performed for the actin cytoskeleton, TJ proteins $\mathrm{ZO1}$ and occludin, AJ protein E-cadherin, the cell nucleus, and VP1 capsid protein. Immunofluorescent staining was carried out using phalloidin Alexa Fluor 660 (1:60, Molecular Probes, USA) and 4'-6-diamidino-2-phenylindole dihydrochloride (DAPI) (concentration 1:50,000) for $60 \mathrm{~min}$ at RT to stain actin and the nucleus, respectively. Primary antibodies, polyclonal rabbit anti-ZO1, anti-occludin, and anti-E-cadherin (Invitrogen, Germany) or monoclonal mouse anti-enterovirus VP1 (Clone 5-D8/1) (Dako, Denmark) were added at a dilution of 1:250 overnight at $4{ }^{\circ} \mathrm{C}$. As secondary antibodies, polyclonal anti-rabbit-IgG Alexa Fluor 488 and 594 were used at a dilution of 1:250 for $1 \mathrm{~h}$ at RT. Images were taken with a Zeiss Apotome and Zen software (Carl Zeiss, Germany) using a $\times 63 / 1.4$ objective lens. For evaluation, Z-stacks of the cell layers were acquired and orthogonal representation enabled immunocytochemical analysis.

For assessment of PMN and T-cell transmigration across the HIBCPP cell layer, an infection experiment over $24 \mathrm{~h}$ with an MOI of 0.7 was carried out. As recently described, $\mathrm{PMN}$ and naïve $\mathrm{CD}^{+}$T-cells were isolated from human blood of healthy donors [23]. Each cell population was labelled either with CellTrace ${ }^{\mathrm{Tm}}$ Calcein red-orange or with CellTrace $^{\text {Tx }}$ Calcein green (Molecular probes, USA) according to manufacturer's instructions. After $24 \mathrm{~h}$ of infection, $4 \times 10^{5} \mathrm{PMN}$ were added into the filter insert. After $2 \mathrm{~h}$ of migration, $4 \times 10^{5}$ naïve $\mathrm{CD}^{+}$T-cells were also added to the filter inserts and both cell populations were incubated for another $2 \mathrm{~h}$ (PMN migration $4 \mathrm{~h}, \mathrm{~T}$-cell migration $2 \mathrm{~h}$ ). Filters were washed twice in PBS and were fixed with 3.7\% formaldehyde for $10 \mathrm{~min}$ at RT. The subsequent migration 
analysis was carried out using immunocytochemical staining of the cell layers as described above.

\section{Western blot}

After $28 \mathrm{~h}$ of infection at an MOI of 0.7, HIBCPP cells were washed with PBS. Modified radioimmunoprecipitation assay (RIPA) buffer (containing $50 \mathrm{mM}$ Tris HCL (pH 8), $150 \mathrm{nM} \mathrm{NaCl}, 0.1 \%$ SDS, $1 \%$ Triton X-100, 1\% natriumdeoxycholate, $1 \times$ protease inhibitor cocktail, $1 \mathrm{mM}$ PMSF, $50 \mathrm{mM} \mathrm{NaF}, 2 \mathrm{mM}$ EDTA, and $1 \mathrm{mM}$ $\mathrm{Na} 3 \mathrm{VO} 4)$ was used to extract whole protein. The lysates were centrifuged at $18620 \times g$ for $10 \mathrm{~min}$, and total protein amount was calculated applying the manufacturer's instructions for the DC Protein Assay according to the Lowry method (BioRad, Germany). A total of $20 \mu \mathrm{g}$ per sample was mixed with loading buffer and was loaded onto a $4-12 \%$ Bis-tris gel (Invitrogen, Germany) followed by overnight blot onto a nitrocellulose membrane using standard conditions. Primary antibodies used for the immunoblotting were rabbit-anti-ZO1, rabbit-anti-occludin, rabbit-anti-E-cadherin (Cell Signaling, UK, all 1:500 dilution), and mouse-anti- $\beta$-actin (Sigma-Aldrich, Germany; 1:10,000 dilution). Secondary antibodies used for detection were either anti-rabbit or anti-mouse horseradish peroxidase (HRP)-conjugated (Millipore, USA; 1:5000 dilution). Visualization was ensured using the respective substrate from Immobilon Western Kit (Millipore, USA).

\section{Transmission electron microscopy}

To further analyze PMN and T-cells migrating across the HIBCPP cells, we prepared filter membranes from different experimental conditions for transmission electron microscopy (HIBCPP + PMN + T-cells \pm chemokine \pm E-30 Bastianni) as described previously [39]. Briefly, after $28 \mathrm{~h}$ of infection and subsequent leukocyte migration, the filter inserts were fixed over night at $4{ }^{\circ} \mathrm{C}$ in $2 \%$ glutaraldehyde/ $0.1 \mathrm{M}$ cacodylate buffer ( $\mathrm{pH}$ 7.4) embedded in Araldite (Science Services, Germany) and ultrathin sections were performed using an ultramicrotome (Ultracut R) (Leica, Germany). Samples were analyzed with a Zeiss Em 10 Transmission electron microscope (Zeiss, Germany).

\section{Focused ion beam/scanning electron microscopy (FIB/SEM)}

For scanning electron microscopy (SEM), gold palladium sputter-coated membranes were attached on specific SEM sample holders. Regions of interest for three-dimensional imaging were decided upon after light microscope analysis of thin cut membrane slices. Serial sectioning imaging was performed with a Zeiss Crossbeam 550 gallium FIB-SEM instrument (Zeiss, Germany) operating at low voltage $(\mathrm{SEM} E H T=1.7 \mathrm{kV})[45,46]$. FIB slices were prepared, and images acquired at variable regions of interest using the ATLAS 3D nanotomography package (Zeiss, Germany) and an energy-selective in-lens backscattered electron detector (EsB) with voxel resolutions of $10 \times 10 \times 10 \mathrm{~nm}$ (sample HIBCPP + PMN + T-cells + E-30 + CXCL12) and $8 \times 8 \times 8 \mathrm{~nm}$ (sample HIBCPP $+\mathrm{PMN}+\mathrm{T}$-cells + E- $30+$ IL8). Two-dimensional image filtering of the raw data (non-local means: both samples; Gaussian: sample $\mathrm{HIBCPP}+\mathrm{PMN}+\mathrm{T}$-cells+E-30 + CXCL12) and threedimensional reconstruction and video visualization were performed without additional slice registration using the commercial software package ORS Visual SI [47].

\section{Quantification of viral genome copies via qPCR}

Quantification of viral genome copies was performed on total RNA extracted from the supernatant and cell lysate collected throughout the infection course. Extraction was automatically performed using the EZ1 Virus Mini Kit (Qiagen', Germany) following the manufacturer's instructions. Quantitative real-time PCR (qPCR) analysis was carried out using quantitative two-step TaqMan qPCR. Primers targeting the 5'UTR region were Ent411F-5'-GACATGGTGCTGAAGAGTCTATTGA-3' and Ent486R-5'-GCTCCGCAGTTAGGATTAGCC-3'. The probe used was Ent443T-5' FAM-GTAGTCCTCCGGCCCCTGAATGC-TAMRA-3' .

Reverse transcription was performed with Ent486R using Sensicript RT (Qiagen, Germany) according to manufacturer's recommendations. Standard protocols and conditions were applied during amplification using a $2 \times$ universalmaster-mix (Applied Biosystems, Germany) on an ABI 7500 thermal cycler (Applied Biosystems, Germany). As standards, plasmids that encompass the amplified region were created and serially diluted after purification. Standard graphs of the $\mathrm{C}_{T}$ values obtained from serial dilutions of the standards (5000, 500, and 50 copies) were constructed and the numbers of specific genomes were calculated by the software. This method was used to analyze the number of viral genome copies, without categorizing in infectious virus and non-encapsidated viral RNA.

\section{Quantification of viral infection via immunofluorescence} HIBCPP cell infection at an MOI of 0.7 with each strain was performed for $28 \mathrm{~h}$ and subsequently the filters were washed with PBS and stained. The immunofluorescent staining for DAPI (HIBCPP nucleus) and viral capsid protein (VP) 1 was performed as described in the "Immunofluorescence analysis of tight and adherens junction proteins and immune cell migration" section of "Methods." Infected cells were identified through the presence of intracellular VP1 staining and compared to the total amount of HIBCPP cells growing on the filter. Percentage of E-30-infected HIBCPP cells was calculated by counting 10 fields of view $(142.1 \mu \mathrm{m} \times 106.48 \mu \mathrm{m})$ per filter in four independent experiments. The overall infection capabilities were calculated using the average amount of 
infected cells per field and multiplied with an area coefficient. The size of the filter membranes was $0.33 \mathrm{~cm}^{2}$.

\section{Complete genomic sequencing}

The RNA was extracted from $140 \mu \mathrm{l}$ of the supernatant of virus-infected cell cultures using the QIAamp Viral RNA Mini Kit (Qiagen, Germany) according to the manufacturer's instructions. Synthesis of the cDNAs from purified RNAs was performed using SuperScript ${ }^{\mathrm{tm}}$ III Reverse Transcriptase (Invitrogen, Germany) according to the manufacturer's instructions. Primers used for amplification and sequencing were designed according to conserved sequences in the whole genome sequences reported in Genbank for Echovirus 30 and are available on request. The amplification was performed by using the Phusion ${ }^{\circ}$ High-Fidelity PCR Master Mix with HF Buffer (New England Biolabs, USA). The 1-4 kbp PCR products obtained were purified using the Gel Extraction Kit (Qiagen, Germany). The nucleotide sequences were determined at GATC (Biotech AG, Germany) with an ABI 3730xl DNA analyzer. Forward and reverse sequencing reactions were carried out with the oligonucleotides used in geneamplification reactions. The sequences were deposited in the GenBank database under accession number KY888272KY888275.

\section{Phylogenetic analysis of echovirus 30 nucleotide sequences}

Nucleotide regions encoding for the capsid proteins (P1 region) were used as a query sequence in a BLAST search against the Genbank non-redundant database. Prototype strains of Echovirus 11 (X80059.1) and Echovirus 6 (AY3025588.1) were used as an outgroup. The sequences were aligned using ClustalW as implemented in MEGA 7.0. A phylogenetic tree was calculated with the neighborjoining method using the Tamura-Nei's model for nucleotide substitution. The reliability of the phylogenetic topologies was determined by bootstrap-resampling test with 1000 replicates.

\section{Statistics}

Statistical analysis was performed using the SAS system, release 9.3 (SAS Institute Inc., Cary, USA). Virus strains (E-30 Bastianni, 13-311, 13-759, and 14-397) and time points were "fixed factors" and the day of the experiment "random factor" in the SAS procedure SAS MIXED which was applied to calculate significance in dextran flux and TEER. For viral load distribution a "Poisson-Regression" using the "Tukey-Kramer" comparison calculation was applied. If not otherwise stated, result values are given as mean + SD and the level of significance is denoted in each figure using either * or \#.

\section{Results}

Alteration of barrier function of HIBCPP cells after infection with E-30 is strain-dependent

To evaluate the effects of infection with different E-30 outbreak strains at an MOI of 0.7 over $28 \mathrm{~h}$ on the barrier integrity of HIBCPP cells, TEER, and the paracellular permeability for dextran were measured at indicated time points. Over the time course of the experiment, the TEER values of the uninfected controls showed no significant changes (Fig. 1a). A similar pattern and also no significant changes were observed upon infection of HIBCPP cells with the strains 13-759 and 14-397 (Fig. 1a). In contrast, both E-30 Bastianni and 13-311 triggered a significant decrease in TEER after 5,24 , and $28 \mathrm{~h}$ of infection compared to respective TEER values measured at the start of the experiment (Fig. 1a). Interestingly, the dextran flux evaluation (Fig. 1b) showed that E-30 Bastianni was the only strain which caused a significant increase in dextran flux with $2.30 \pm 1.46 \%$ diffusion across the HIBCPP layer compared to the uninfected control $(p=0.0020)$. Strains 13$311(1.18 \pm 1.31 \%), \quad 13-759(0.63 \pm 0.90 \%)$, and $14-397$ $(0.45 \pm 0.42 \%)$ did not cause a significant increase in paracellular permeability and the values remained comparable to the uninfected control $(0.94 \pm 1.06 \%)$ (Fig. 1b).

\section{E-30 strain-dependent alterations of the morphology of tight and adherens junctions}

As the barrier function of HIBCPP cells is mainly established via a complex network of TJs similar to other polarized epithelial cells $[42,48]$, we were interested in the morphology of $\mathrm{TJ}$ and $\mathrm{AJ}$ following infection with the different E-30 strains, which we analyzed via immunofluorescence analysis of ZO1, occludin, and E-cadherin (Figs. 2, 3, and 4). In the uninfected controls, a continuous "puzzlelike" staining of ZO1 was detectable (Fig. 2). It is expected localization, at the apical side of the cell, was verified with the orthoscopic view. Infection with E-30 Bastianni or 13311 led to extensive disruption of $\mathrm{ZO} 1$ of infected neighboring HIBCPP cells (Fig. 2). The ZO1 of uninfected HIBCPP cells within the same layer of cells was not affected. Similar effects were observed for occludin after infection of HIBCPP cells with E-30 Bastianni or 13-311 (Fig. 3). In contrast, the strains 13-759 and 14-397 had no apparent effect on ZO1 and occludin topology (Figs. 2 and 3). At the level of AJs, both the infection with E-30 Bastianni and to a much lesser extent with 13-311 led to alterations of the morphology (Fig. 4). However, the strains 13-759 and 14-397 had no effect on E-cadherin morphology (Fig. 4). Actin staining remained unaffected under any condition (Figs. 2, 3, and 4; column 2).

To exclude that differences in cytotoxicity of the different E-30 strains were responsible for the observed effects on the morphology of $\mathrm{TJ}$ and $\mathrm{AJ}$, we tested both the viability and release of LDH from HIBCPP cells upon infection 

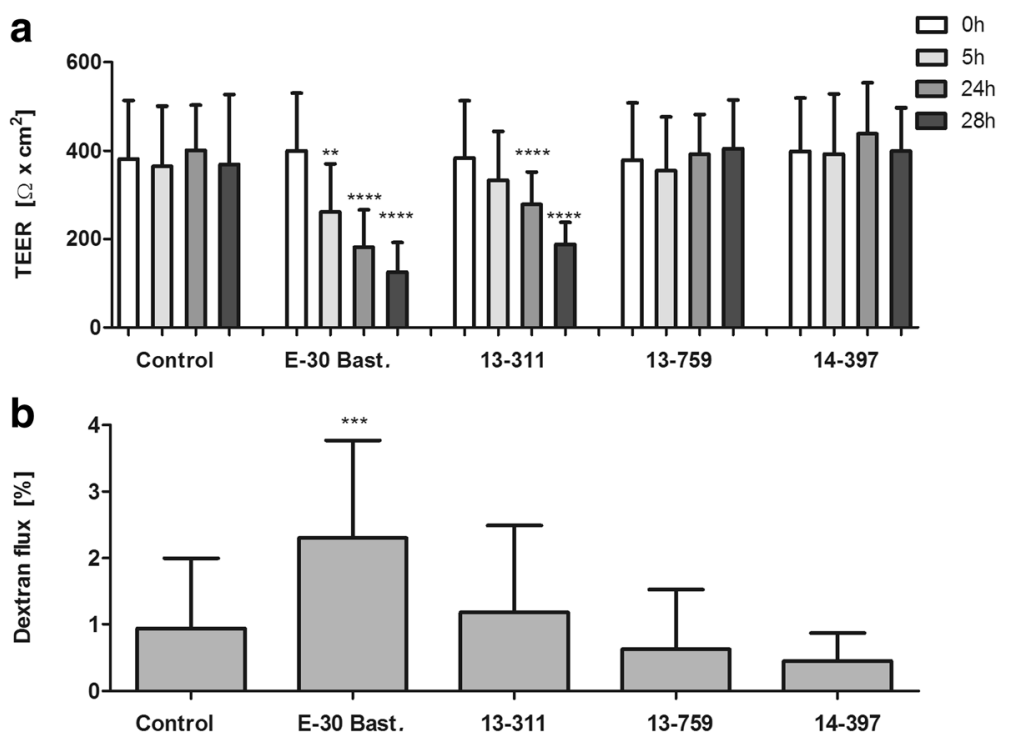

Fig. 1 E-30 strain-specific effects on barrier integrity of HIBCPP cells Barrier integrity of HIBCPP cells was evaluated via measurement of the transepithelial electrical resistance (TEER) (a) and the paracellular permeability for the low molecular weight molecule dextran-TexasRed (3000 kDa) (b) at indicated time points after infection with E-30 Bastianni, 13-311, 13-759, or 14-397 and compared to uninfected controls (a) TEER values at the start of the experiment (white bars), after $5 \mathrm{~h}$ (light gray), after $24 \mathrm{~h}$ (medium gray) and after $28 \mathrm{~h}$ (dark gray) are shown. Data are shown as mean + SD of 11 independent experiments carried out in triplicates. $p$ values compare the TEER at 5, 24, and $28 \mathrm{~h}$ after infection for each viral strain with the respective control at $0 \mathrm{~h}$ $\left({ }^{* *} p<0.01,{ }^{* * * *} p<0.0001\right)$. b Evaluation of the paracellular permeability was carried out after $24 \mathrm{~h}$ of infection of HIBCPP cell layers with different viral strains via the addition of dextran to the upper compartment of the filter for $4 \mathrm{~h}$. Data shown are mean + SD of five independent experiments each performed in triplicates. $p$ values were calculated when comparing paracellular permeability of all infected and uninfected conditions to E-30 Bastianni infected HIBCPP cells $\left({ }^{* * *} p<0.001\right)$

with E-30. Analysis of viability after $28 \mathrm{~h}$ of infection showed no significant increase in dead cells for any of the viral strains compared to the uninfected control (Additional file $1 \mathrm{~A}$ ). As a second parameter, we measured LDH release. These measurements indicated only minor effects of all E-30 strains on HIBCPP cells when compared to uninfected controls, but no significant strain-dependent differences (Additional file 1B).

\section{Junctional protein expression in HIBCPP after E-30 infec- tion is not altered}

As we observed, strain-specific alterations to the morphology of TJ and AJ of the infected HIBCPP cells were investigated, whether protein expression was affected in a comparable manner. These findings indicate that protein expression of the TJ proteins ZO1 $(220 \mathrm{kDa})$ and occludin $(65 \mathrm{kDa})$ as well as of the AJ protein E-cadherin $(120 \mathrm{kDa})$ was not considerably altered (Fig. 5).

\section{Infection with E-30 promotes paracellular and transcellu- lar PMN and T-cell transmigration}

Based on previous observations at the BBB and BCSFB, we hypothesized that the preferred migration pathway of leukocytes during sequential transmigration into the CNS may be dependent on the level of barrier impairment. Therefore, we carried out extensive analyses, applying IF staining, TEM and FIB/SEM, and captured PMN and T- cells during their passage across the HIBCPP layer. When analyzing images from IF, the location of the immune cell actin skeleton in relation to the actin cytoskeleton of the HIBCPP cells indicates both para- and transcellular transmigration with or without E-30 infection (Fig. 6). The surrounding of leukocytes by intercellular actin borders which are connected to the apical epithelial cell membrane is in favor of paracellular diapedesis (white arrowheads in Fig. 6b-f). We could also visualize an elongated PMN body squeezing through the cell borders of HIBCPP cells indicating paracellular diapedesis (Fig. 6c, d). In contrast, when the migrating immune cell is localized in clear distance to the actin cytoskeleton of the HIBCPP cells, transcellular diapedesis is more likely. As shown in Fig. $6 \mathrm{~g}$, $\mathrm{h}$, in an experiment involving infection with E-30 Bastianni, the body of a transmigrating PMN is in clear distance to the HIBCPP cell membrane indicating transcellular PMN migration.

In order to verify the observations made during IF staining analysis, we further carried out a thorough electron microscopic analysis. Here, we could confirm the IF analysis (Fig. 7). In Fig. 7a-b paracellular, in Fig. 7c-h transcellular migrations of leukocytes are shown. Paracellular PMN migration could be confirmed through the, often elongated, PMN pushing between the cell borders of neighboring epithelial cells, migrating from the basolateral cell side towards the apical lumen (Fig. 7a). In the enlargement, the 

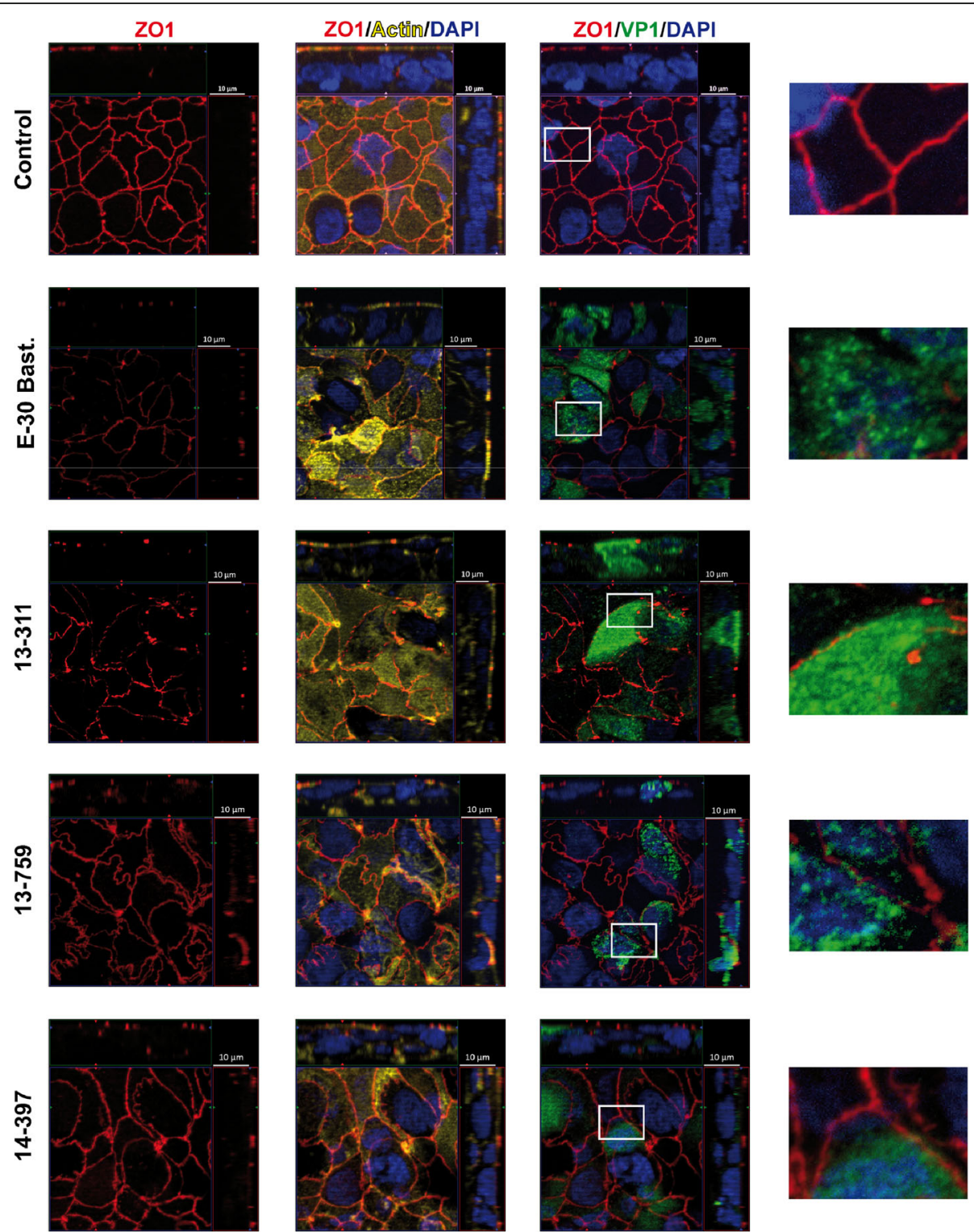

Fig. 2 E-30 infection of HIBCPP cells leads to strain-dependent alteration of the TJ morphology involving ZO1. HIBCPP cells were infected with E-30 Bastianni, 13-311, 13-759, and 14-397 for $28 \mathrm{~h}$ and ZO1 staining was compared to uninfected controls. Cell layers were stained for nuclei with 4, 6diamidino-2-phenylindole (DAPI) (shown here in blue), actin cytoskeleton with Phalloidin (shown here in yellow), the viral capsid protein 1 (VP1) (shown here in green) and ZO1 (red). Z-stack images were taken from regions with infected cells using an Apotome and represented through display of a cross-section through the z-plane of multiple slices in combination with a two-dimensional view from the top of the cell layer. For each strain we included a 400x enlarged image of an area which we considered a representative frame. The polarized cells are oriented with the apical side pointing up or to the right and basolateral downwards or to the left. Three images per strain showing different grouping of parallel staining in combination with a zoomed in view are displayed horizontally (column one: only ZO1; column two: DAPI, actin, and ZO1; column three: DAPI, VP1, and ZO1); E-30 strains are listed vertically. The images shown are representative examples of multiple stainings taken from six independent experiments each performed in duplicates

PMN is visible directly in front of the intact cellular junction complex (Fig. 7b). Besides, undergoing paracellular transmigration PMN were also observed to migrate via the transcellular route (Fig. 7c, d). The PMN cell membrane (small arrows) and extensions in the direction of the migration process (thick arrow) were observed (Fig. 7d). A T-cell that is just about to exit the HIBCPP cell on its apical side, whilst still connected through dense actin filament to the plexus epithelial cell, demonstrates the transcellular route (Fig. 7e, f). Finally, a most likely transcellular migrating T-cell is shown that is leaving the monolayer, but is still connected with HIBCPP cell over a larger area of the apical membrane (Fig. $7 \mathrm{~g}, \mathrm{~h}$ ). 

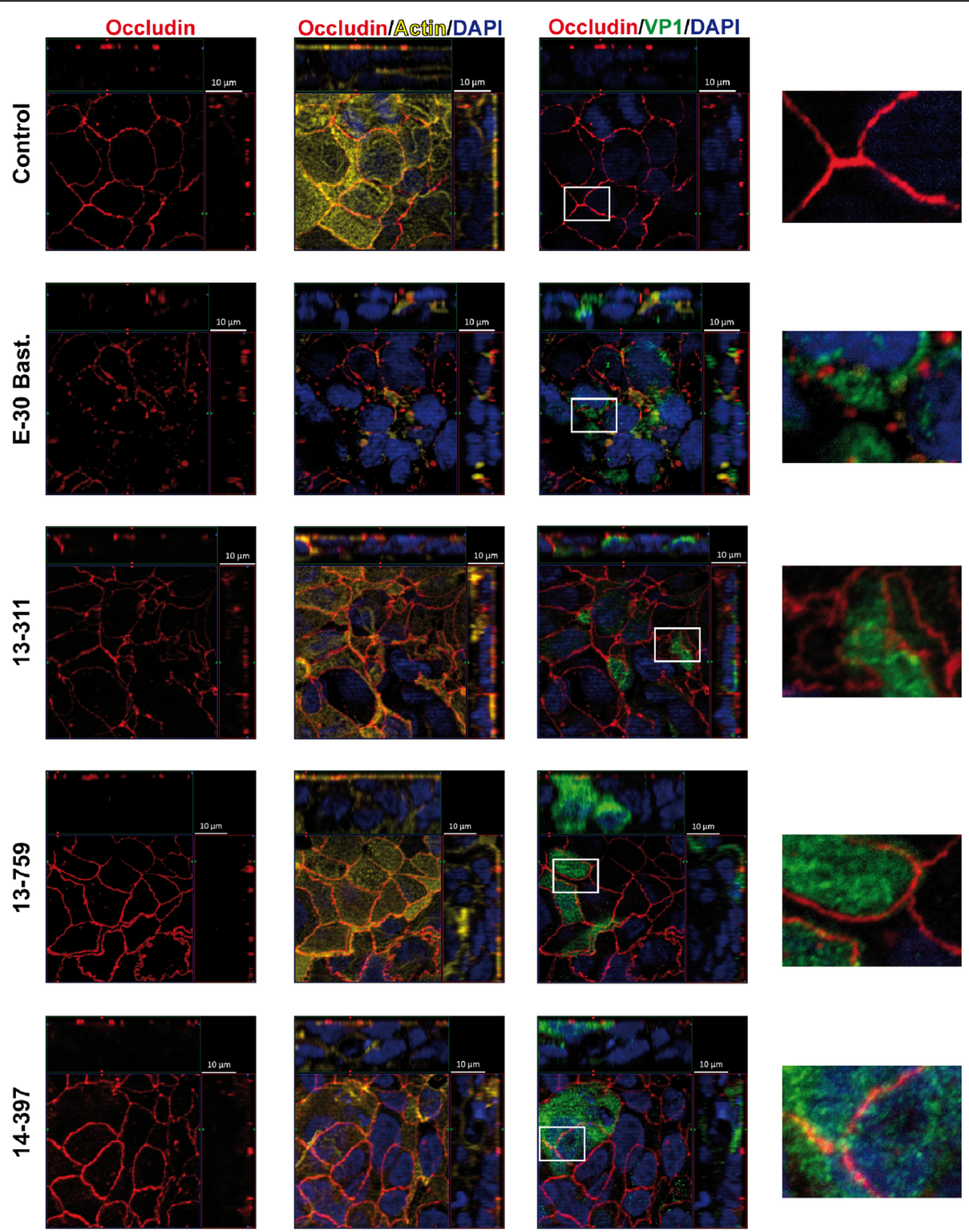

Fig. 3 E-30 infection of HIBCPP cells leads to strain-dependent alteration of TJ morphology involving occludin. HIBCPP cells were treated analogous to procedures described for Fig. 2. Cell layers were stained for nuclei with DAPI (shown here in blue), actin cytoskeleton with phalloidin (shown here in yellow), VP1 (shown here in green) and occludin (red). For detailed description of image acquisition and preparation please refer to Fig. 2. Three images per strain showing different grouping of parallel staining in combination with a zoomed in view are displayed horizontally (column one: only occludin; column two: DAPI, actin, and occludin; column three: DAPI, VP1, and occludin); E-30 strains are listed vertically. The images shown are representative examples of multiple stainings taken from six independent experiments each performed in duplicates

For leukocyte migration pattern analysis across cellular layers a three-dimensional reconstruction of the migrating cell and its surrounding is of great advantage. We therefore performed FIB/SEM tomography of the HIBCPP layer with migrating leukocytes to further characterize the migration pathways. We could again demonstrate the paracellular migration of a PMN between two adjacent HIBCPP cells (Fig. 8a, b; Additional files 2, 3, 4, and 5; condition HIBCPP+PMN + T-cells+E-30 + IL8). The PMN is just about to enter the cell layer from the basolateral side and two separate membranes of the PMN and the adjacent HIBCPP cells are clearly observed (Fig. 8a, b; arrowheads). Thus, we could identify cellular borders and intercellular gaps, which are formed during paracellular movement of the PMN (arrowheads). When adding all slices into the three-dimensional construct, we could identify that the visible PMN is entering the HIBCPP layer from the basolateral side through the filter pore (Additional files 2, 3, 4, and 5). The PMN squeezes through the pores of the membrane moving from the basolateral 

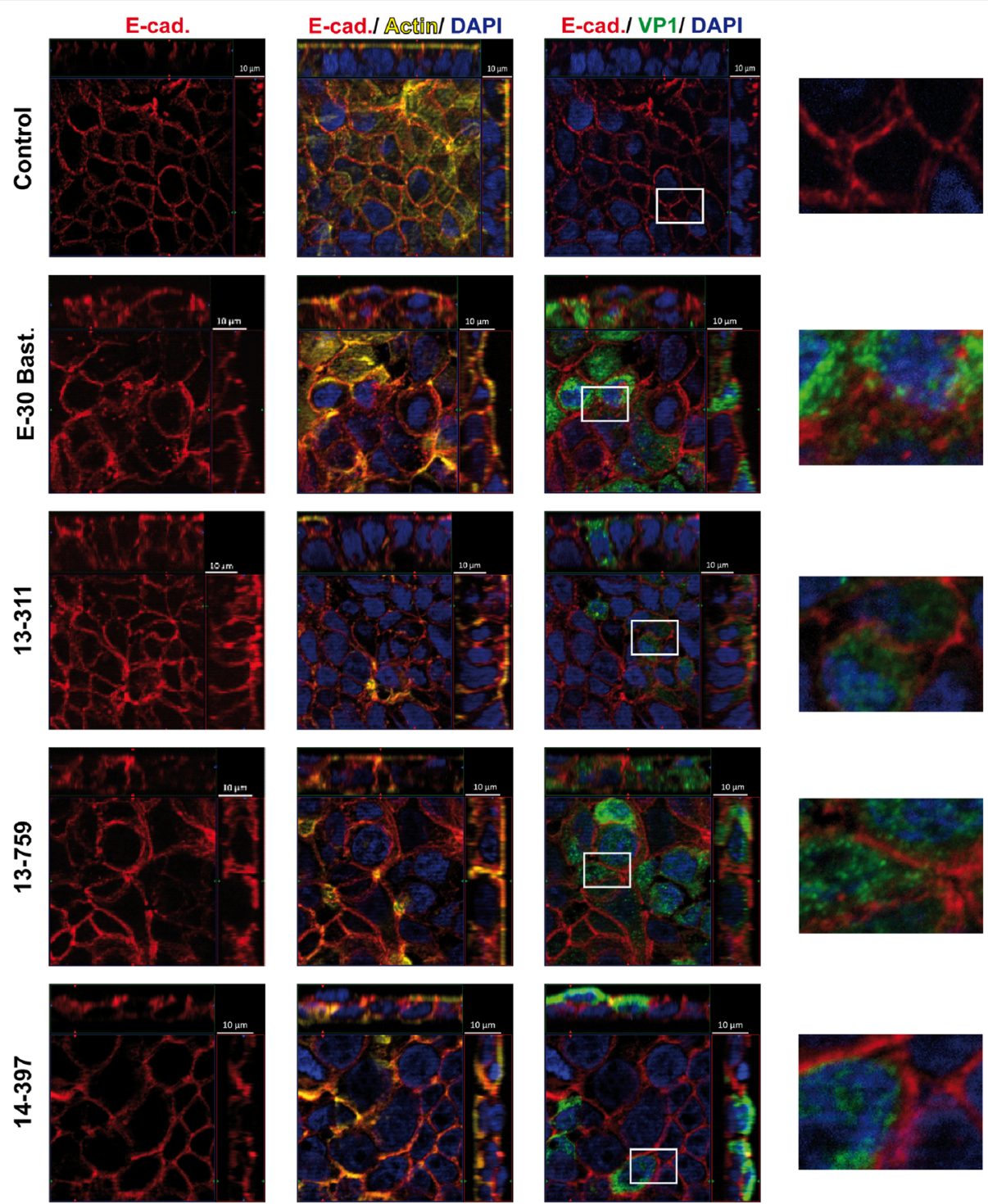

Fig. 4 E-30 infection of HIBCPP cells leads to strain-dependent alteration of AJ morphology involving E-cadherin. HIBCPP cells were treated analogous to procedures described for Fig. 2. Cell layers were stained for nuclei with DAPI (shown here in blue), actin cytoskeleton with phalloidin (shown here in yellow), VP1 (shown here in green), and E-cadherin (red). For detailed description of image acquisition and preparation, please refer to Fig. 2. Three images per strain showing different groupings of parallel staining in combination with a zoomed in view are displayed horizontally (column one: only E-cadherin; column two: DAPI, actin, and E-cadherin; column three: DAPI, VP1, and E-cadherin); infection strains are listed vertically. The images shown are representative examples of multiple stainings taken from six independent experiments each performed in duplicates

HIBCPP cell side towards the apical cell side. In the flight mode of Additional file 4, the probe is demonstrated as a cube and sliced along the $x$ - and $z$-axis. In the Additional file 5 the non-local means projection is visualized. We further analyzed a second stimulation condition (HIBCPP + PMN + T-cells + E-30 + CXCL12), where the transcellular migration of a T-cell is displayed (Fig. 8c, d, Additional files 6, 7, and 8). The T-cell paves its way from the basolateral to the apical cell side (arrowheads). The video of Additional file 6 shows serial images of the raw data. Additional file 7 shows the same data with inverted grey-level distribution. Here, the clear distance to the
HIBCPP cell borders is demonstrated and that the T-cell lies within the HIBCPP cell body. Lastly, in the Additional file 8 shows projections of the three-dimensional volume (after two-dimensional Gaussian and non-local means filtering of the raw data).

\section{Distinct E-30 strain-dependent replication efficacy in HIBCPP and RD cells}

To explore possible reasons for the strain-dependent observed effects on barrier function and morphology, we first focused on calculating the amount of infected HIBCPP cells after infection with each strain. After 


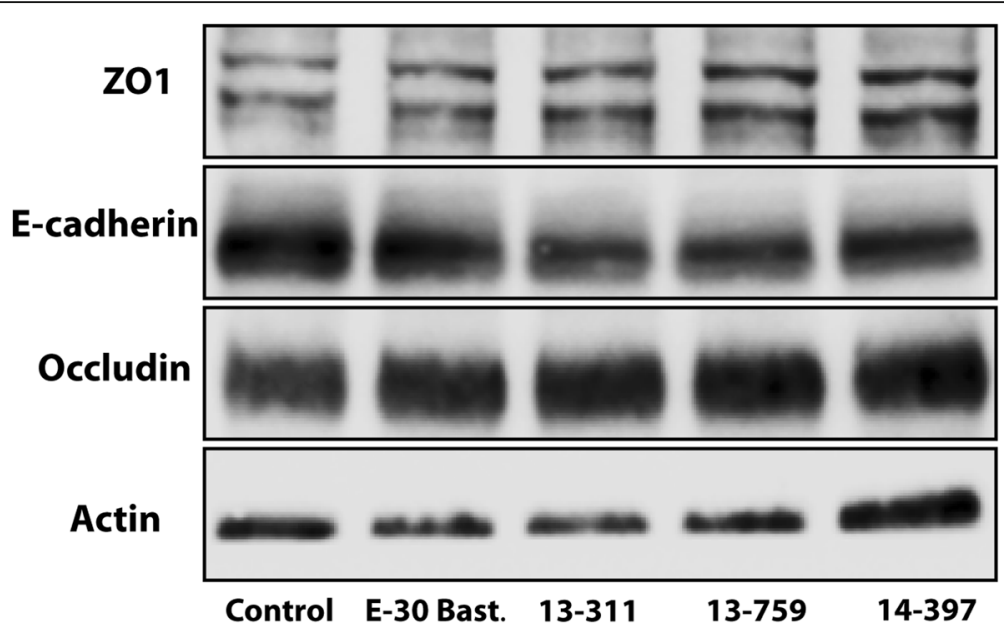

Fig. 5 E-30 infection of HIBCPP cells does not affect tight and adherens junction whole protein expression. Western blot of total protein lysate of HIBCPP cells after $28 \mathrm{~h}$ of infection with E-30 Bastianni, 13-311, 13-759, and 14-397 and of uninfected control samples. Antibodies were directed against ZO1 (220 kDa), E-cadherin (120 kDa), occludin (65 kDa), and actin (42 kDa). Experiments were carried out in triplicates, and a representative blot was used for illustration taken from of six independent experiments

$28 \mathrm{~h}$, significantly more cells were infected by E-30 Bastianni $(2.7940 \pm 0.7012 \% p<0.0001)$ compared to the outbreak strains. In addition, strain 13-311 $(0.5071 \pm 0.0858 \%)$ infected significantly more HIBCPP cells than strain $14-397 \quad(0.1836 \pm 0.0713 \% \quad p<$ 0.0001)]. There was no significant difference between strain $13-311(0.5071 \pm 0.0858 \%)$ and strain $13-759$ $(0.3544 \pm 0.2335 \%)$ (Fig. 9a).
To further characterize the viral strains, we monitored the distribution of viral genomes within our in vitro system and determined the percentage of cell-associated virus or viral genomes recovered from the basolateral or apical HIBCPP cell supernatant. After $5 \mathrm{~h}$ exclusively for E-30 Bastianni already $33 \pm 18 \%$ of the total viral genomes were found within the HIBCPP cells. For the outbreak strains most of the viral genomes were still
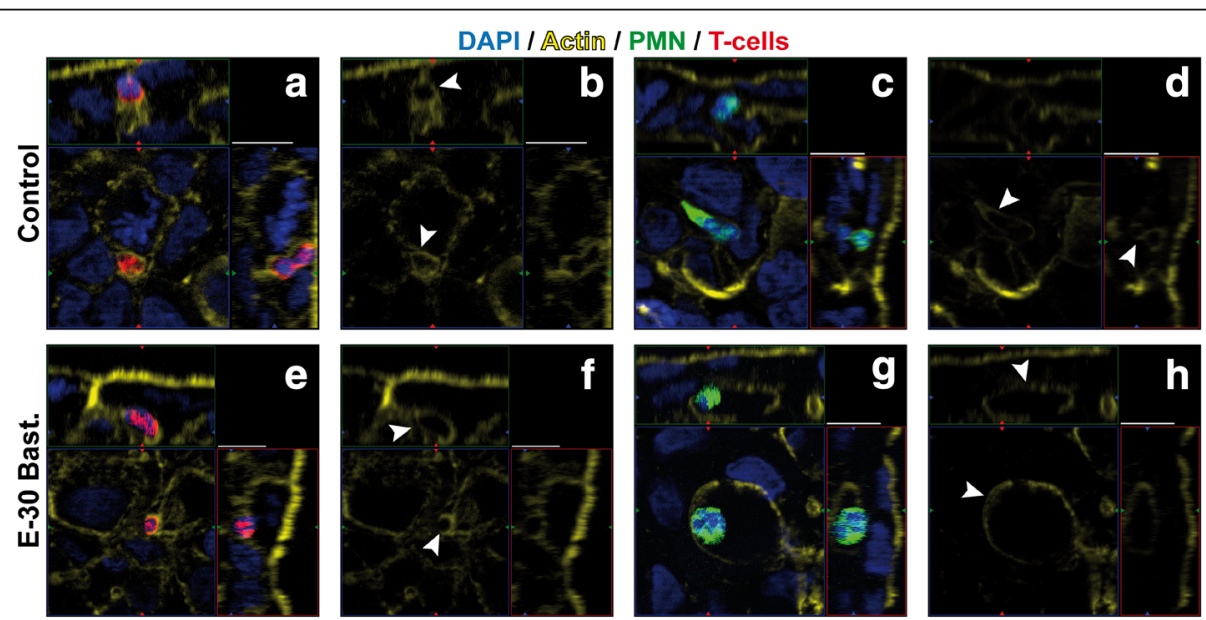

CXCL12

IL8

Fig. 6 Immunofluorescence analysis of leukocyte migration pathway across the HIBCPP. Immune cell migration across HIBCPP monolayers infected with E-30 Bastianni was analyzed using immunofluorescent staining. Infection for $28 \mathrm{~h}$ with E-30 Bastianni was carried out before staining the filters for nuclei with DAPI (shown here in blue), actin skeleton with phalloidin (shown here in yellow), PMN (shown here in green), and T-cells (shown here in red). For detailed description of image acquisition and preparation, please refer to Fig. 2. Image pairs show regions of interest and a single channel view of actin expression. White arrowheads indicate the localization of the leukocyte in relation to the actin skeleton. The surrounding of leukocytes by intercellular actin borders which are connected to the apical epithelial cell membrane is in favor of paracellular diapedesis $(\mathbf{b}$, $\mathbf{d}$, $\mathbf{f})$, whereas the

localization of the leukocyte in clear distance of the actin skeleton is in favor of transcellular diapedesis (h). Images were taken for each of the following conditions: HIBCPP cells + PMN and T-cells + CXCL12 $=\mathbf{a}, \mathbf{b} ;$ HIBCPP cells + PMN and T-cells + E-30 Bastianni + CXCL12 $=\mathbf{e}, \mathbf{f} ;$ HIBCPP cells + PMN and Tcells $+I L 8=\mathbf{c}, \mathbf{d} ;$ HIBCPP cells + PMN and T-cells $+E-30$ Bastianni $+I L 8=\mathbf{g}, \mathbf{h}$. These are representative images of three independent experiments, each carried out in duplicates and analyzed with a minimum of four z-stacks per filter 

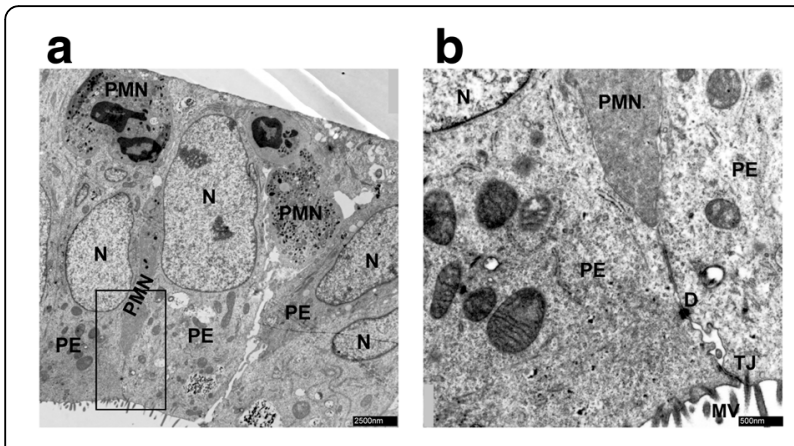

\section{c}
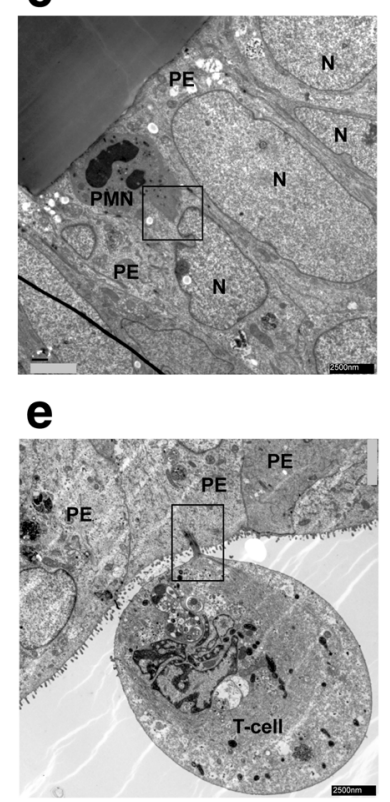

\section{g}

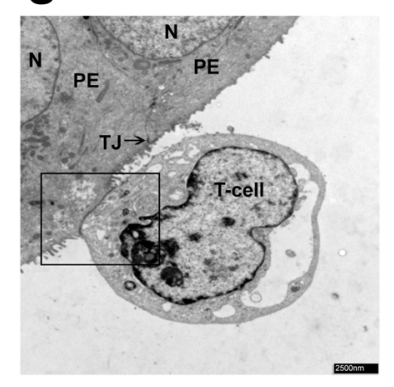

d

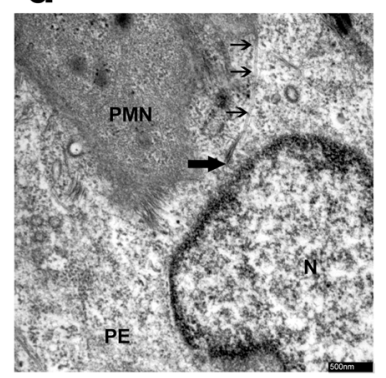

f

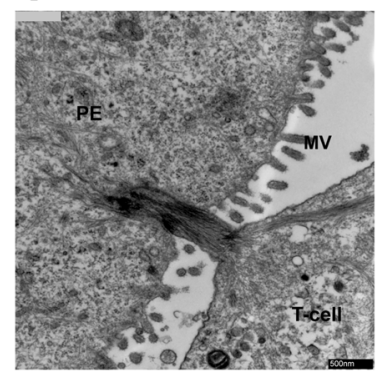

h

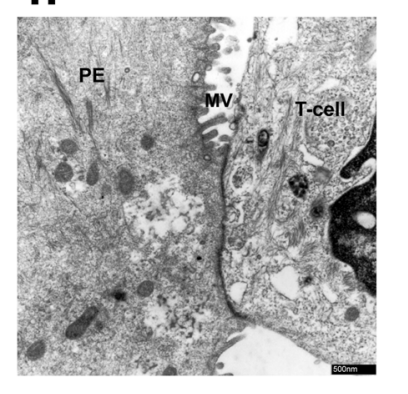

Fig. 7 Transmission electron microscopic analysis of migration pathways of immune cells across the HIBCPP cells. Migration pathways of PMNs and naive T-cells across HIBCPP cells were identified through electron microscopy. Images were taken for each of the following conditions: HIBCPP cells + PMN + T-cells + CXCL12 = a, b; HIBCPP cells + PMN + T-cells + CXCL12 +E-30 Bastianni $=\mathbf{c}$, $\mathbf{d}$, and g, h. HIBCPP cells + PMN + T-cells + IL8 + E-30 Bastianni $=\mathbf{e}$, $\mathbf{f}_{\text {; The }}$ horizontal image pairs are an overview and an enlarged frame of the HIBCPP cell layer with migrating leukocytes. $(\mathbf{a}, \mathbf{b})$ Paracellular migration of PMN can be identified, as the elongated PMN is squeezing through tight epithelial cells. (c, d) Transcellular migration of PMN, entering the cell layer from the basolateral side; single arrow = cell membrane; thick arrow = end of membrane. (e, f) Transcellular T-cell migration can be seen, as the leukocyte is leaving the cell layer towards the apical HIBCPP cell side. Cellular connection through actin filament is in clear distance from intact TJ $(\mathbf{g}, \mathbf{h})$. Transcellular T-cell migration is visible and confirmed through the connection between the T-cell and the HIBCPP cell at clear distance from intact TJ. These are representative images of two independent experiments, each carried out in triplicates. Scale bar A, C, E, and I: $2500 \mathrm{~nm}, \mathrm{~B}, \mathrm{D}, \mathrm{F}$ and H: $500 \mathrm{~nm}$. N = Plexus epithelial cell nucleus; $\mathrm{PE}=$ plexus epithelial cell, $\mathrm{D}=$ desmosome, $\mathrm{MV}=$ microvilli, $\mathrm{TJ}=$ tight junctions, $\mathrm{PMN}=$ polymorphonuclear neutrophil

located in the basolateral filter compartment (Fig. 9b). After $24 \mathrm{~h}$ for E-30 Bastianni $31 \pm 11 \%$ of viral genomes were found in the apical and $20 \pm 15 \%$ were detected in the basolateral filter compartment. In comparison, for strains 13-311, 13-759, and 14-397, $17 \pm 1 \%, 16 \pm 8 \%$, and $16 \pm 9 \%$, respectively, were detectable within the apical filter compartment at this time point. Strain 13-311 and 13-759 showed similar distribution with $35 \pm 7 \%$ and $37 \pm 2 \%$ found in the basolateral supernatant and 47 $\pm 7 \%$ and $47 \pm 6 \%$ cell-associated viral genomes. Noteworthy, strain 14-397 behaved different to the other strains with only $12 \pm 12 \%$ of the viral genomes located within the cells, but a majority of viral genomes $72 \pm$ $18 \%$ were still detected basolaterally (Fig. 9b). Moreover, in contrast to the other outbreak strains, the pattern of the distribution of viral genomes of strain 14-397 does not vary between 5 and $24 \mathrm{~h}$ of infection. The prolongation of the infection period to $48 \mathrm{~h}$ does not change the pattern of effects on barrier integrity and viral particle distribution of the different strains on HIBCPP cells (Additional file 9). Although 13-759 and 13-311 are comparable concerning viral particle distribution and replication rates (Fig. 9b, c), they show opposing effects on barrier integrity (Additional file 9). 14-397 is not catching up in regard of replication rate (Additional file 9). Interestingly, for all E-30 strains, their progeny harvested at the apical side of the cellular barrier was infectious (Additional file 10). Still, the strain E-30 Bast. was causing the strongest cytopathic effect on RD cells, whereas the outbreak strains showed less (13311>> 13-759 > 14-397) (Additional file 10).

In HIBCPP cells, in contrast to strong viral replication rates measured via $\mathrm{QPCR}$ as viral genome copies/ml for E- 

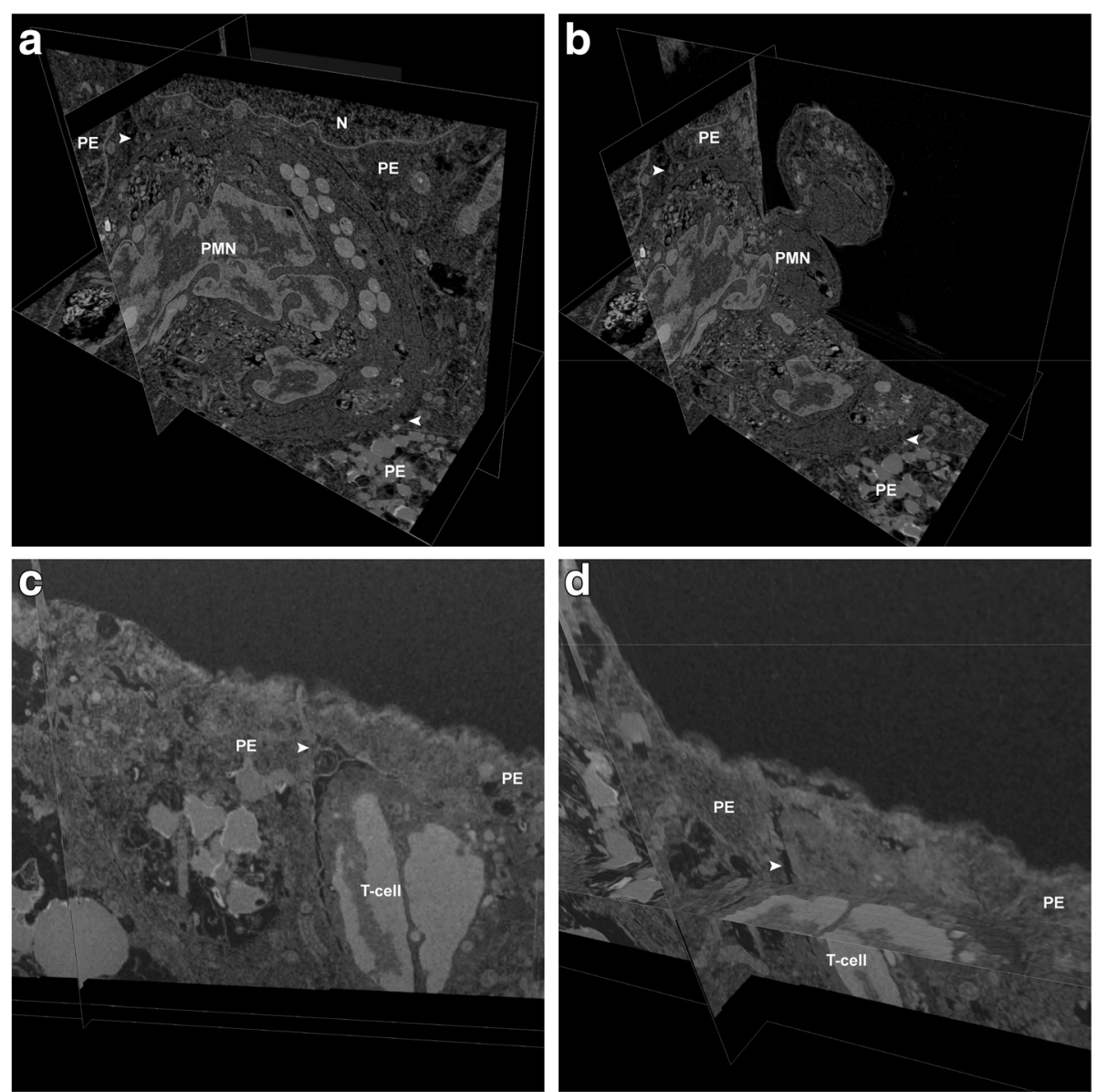

Fig. 8 Focal ion beam microscopy analysis of migration pathway of PMN and T-cells cells across the HIBCPP cells. Further analysis of the migration pathway of PMN and T-cells over uninfected and infected HIBCPP cell layers. Shown here are 3D images from HIBCPP + E-30 Bastianni + PMN + T-cells + IL8 $(\mathbf{a}, \mathbf{b})$ and HIBCPP + E-30 Bastianni + PMN + T-cells + CXCL12 (c, $\mathbf{d})$. The first pair of images $(\mathbf{a}, \mathbf{b})$ shows a PMN moving paracellularly between choroid plexus epithelial cells (PE) and was taken from freeze-frames from Additional file 5. Clear intercellular gaps are visible around the periphery of the PMN and especially at the tricellular borders (arrowheads). The PMN is moving through the pore, into the HIBCPP layer, and in between HIBCPP cells. c, d Illustrate a transcellular migration of a T-cell across a HIBCPP cell with clear distance to any cell junction complex. These images were taken from freeze-frames from Additional file 8. Labelled are $\mathrm{N}=$ epithelial cell nucleus; PE = plexus epithelial cell, PMN = polymorphonuclear neutrophil

30 Bastianni, all three outbreak strains showed lower replication rates in a comparable range (Fig. 9c). Still, there was a trend for the 14-397 strain showing the lowest replication rate over the time course of the experiment (Fig. 9c). To investigate whether the differences in viral replication cycles between E-30 Bastianni and the outbreak strains were unique for HIBCPP cells, we carried out infection experiments with the outbreak strains in RD cells (Fig. 9d). Interestingly, the time kinetics of viral replication in RD cells differed. In both cell types, E-30 Bastianni showed the fastest replication cycles, multiplying within $24 \mathrm{~h}$ from $2.74 \times$ $10^{5} \pm 9.95 \times 10^{4}$ to $4.85 \times 10^{7} \pm 2.46 \times 10^{7}$ viral copies $/ \mathrm{ml}$ in HIBCPP cells and from $3.43 \times 10^{4} \pm 3.97 \times 10^{2}$ to $1.60 \times$ $10^{8} \pm 1.69 \times 10^{8}$ in RD cells. Overall, in contrast to the behavior in HIBCPP cells, the outbreak strains do not show defects in the viral replication cycles in RD cells (Fig. 9c, d).
The pattern of viral replication of the different outbreak strains after $5 \mathrm{~h}$ was comparable to the pattern observed for HIBCPP cells at $24 \mathrm{~h}$. Still, after $24 \mathrm{~h}$ of infection, the three outbreak strains reached comparable levels of viral replication in RD cells (Fig. 9c, d).

\section{Outbreak strains differ in nucleotide and amino acid sequences}

Genetic evolution of viral strains may lead to important variation in their genotypes, which can influence their phenotypes, i.e., viral replication within human host cells [49]. Consequently, we sequenced, aligned, and compared the genomes of all used strains (Additional files 11 and 12). The full genomes showed 81.1-81.6\% nucleotide (nt) and 96.0-96.4\% amino acid (aa) identities with E-30 Bastianni, and 83.4-99.1\% nt and 96.6-99.5\% aa 


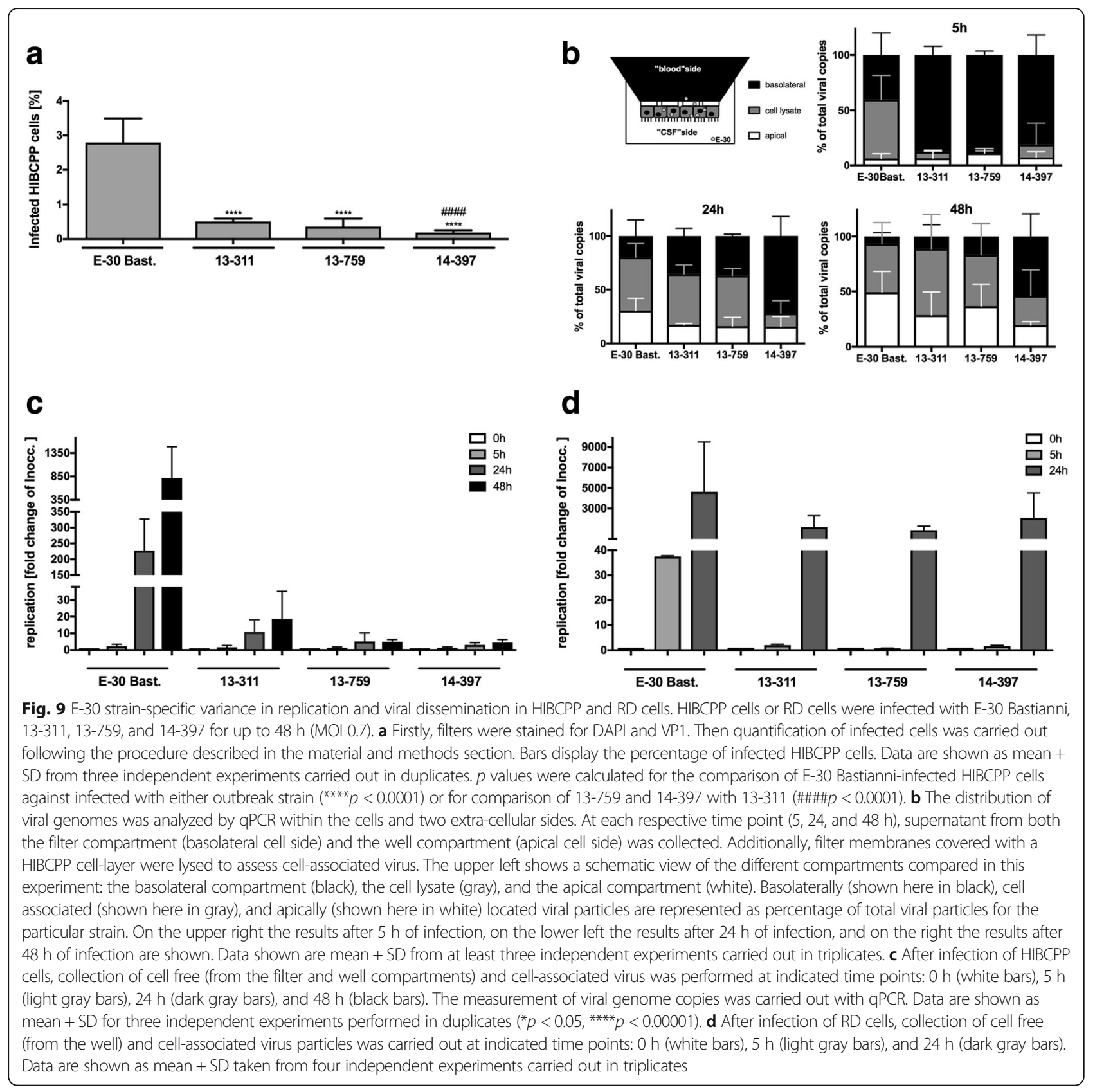

similarity with each other. Alignment of polyprotein sequences identified several clusters of the frequent aa variations between the isolates and E-30 Bastianni. These clusters were mostly located at $15-24,573-655,690-725$, 831-886, and 1043-1157 aa positions of the P1 and P2 regions (Additional files 11 and 12). Among these were eight mutations that located in the solvent-exposed areas of the VP1 protein [50]. Additional point variations were equally allocated all over the polyprotein sequences. Interestingly, only 10 aa differences were found between the polyprotein sequences of the isolates 13-311 and 14397: T15S, S47T, E227G, T463A, A513V, A578T, P826Q,
L1104P, V1801I, and V2121I (Additional file 11). Contrary, the 13-759 strain was markedly different displaying 70 and 74 aa differences, when compared to the isolates 13-311 (Additional files 11 and 12) and 14-397, respectively.

The genetic relationships between the isolated strains and other E-30 strains sequences retrieved from GenBank were investigated by constructing neighbor-joining nt phylogenies for the complete P1 nucleotide regions. (Fig. 10). Both, the 13-311 and 14-397 strains belonged to a cluster, containing viruses isolated mostly in China (2003-2012), but also older European strains (19892000). Closest phylogenetic relationships were observed 
with the JX976773/CHN/2010 strain (96.6-96.7\% nt identity). On the other hand, the 13-759 strain was genetically closely related to the strains that were circulating in France (96.9-97.2\% nt, KF920598- KF920600/FRA/ 2013). With the use of RDP4 Software and several algorithms no recombination events for 13-759 could be detected (data not shown).

\section{Discussion}

The pathogenesis of Echovirus $30 \mathrm{CNS}$ infections is not fully understood. In particular, a thorough insight into the emergence, transmission dynamics and virulence of different NPEV sero- and genotypes is currently lacking [6]. Especially, shifts in genotypes seem to impact the prevalence and occurrence in meningitis outbreaks with E-30 [51].

Additionally, the BCSFB has been identified as a possible entry site for viral pathogens and leukocytes into the CNS $[13,52]$. At the level of the BCSFB, barrier integrity is regulated via a complex network of $\mathrm{TJ}$ and $\mathrm{AJ}$ proteins that may limit and regulate pathogen entry and leukocyte transmigration [22, 42, 53]. During viral infection, the involvement of the proteins $\mathrm{ZO} 1, \mathrm{ZO} 2$, and $\mathrm{ZO} 3$ at the level of the TJs, and cadherins and nectins at the level of the AJs has been confirmed [53, 54].

Application of the HIBCPP cells in an in vitro cell culture model has proven to enable the investigation of E-30 infection of human choroid plexus epithelial cells mimicking the BCSFB in vivo and to analyze barrier alterations and specific immune responses after infection. In our previous work, we have shown that E-30 infects HIBCPP cells from both the basolateral and apical cell sides and infection elicits a specific chemokine expression and leukocyte migration pattern $[19,23]$. In this in vitro model consisting of HIBCPP cells, we now investigated specific effects of three E-30 outbreak strains, isolated in Germany in 2013, in comparison to E-30 Bastianni to evaluate the impact of different genotypes within our model. Moreover, even though E-30 Bastianni is considered the prototype E30 strain, we were interested in data with currently in Germany circulating genotypes.

Interestingly, infection with the three different outbreak strains led to diverse effects on the intact barrier of HIBCPP cells in vitro. Changes in barrier integrity were explicitly observed after the infection with 13-311 or E-30 Bastianni. Furthermore, a correlation of the decrease in TEER, as a parameter for barrier function, and changes in the TJ and AJ morphology, i.e., the presentation of ZO1, occludin and to a lesser extent E-cadherin, in immunofluorescence was possible. A change in the expression of $\mathrm{TJ}$ proteins may be of major importance for an intact barrier and TJ morphology. Western blot analyses did not show any virus-induced changes to $\mathrm{ZO1}$, occludin or E-cadherin protein expression after $28 \mathrm{~h}$ of infection. This might be due to the overall low percentage of infected cells that allows observation of $\mathrm{T}$ ) alterations (e.g., degradation of associated proteins at affected cells) in the IF analysis, but not in the western blots, were all cells of the layer, including those not affected, are taken into account.

It has previously been shown that different NPEV serotypes affect the barrier of endothelial cells divergently [17]. For the BBB, investigation in brain endothelial cells (hCMEC/D3) revealed that different enterovirus serotypes caused varying effects on the barrier integrity. Cytolytic E-6, E-11, E-12, and E-30 majorly impaired the endothelial barrier, resulting in decreased TEER, increased paracellular permeability, and reduction in actin staining. In contrast, EV-A71 and coxsackievirus group $\mathrm{B}$ (CV-B) types had no impact on barrier integrity [17]. At the level of the $\mathrm{BBB}$, in vitro studies involving other viruses could identify strain-specific effects on BBB permeability for three mouse hepatitis virus (MHV) variants during infection of immortalized mouse endothelial cells (bEnd.3). These effects were attributed to alterations in the barrier proteins ZO1, occludin, and E-cadherin on both RNA and protein levels. Despite all three serotypes that affect the barrier integrity, only the MHV3 strain was able to cross the BBB [55].

At epithelial barriers, it has been shown that CV-B3 infection of polarized epithelial cells (Caco-2 cells) led to a reduction in TEER and an increase in paracellular permeability of mannitol and dextran [56]. A direct link between viral impact on $\mathrm{TJ}$ morphology and changes in the TEER has also been shown in human retinal pigment epithelial (HRPE) cells after infection with HIV-1. Infection led to a decrease in TEER, which was in accordance with increased paracellular movement of sodium fluorescein. The reduced barrier integrity was linked to the downregulation of various junctional proteins, such as ZO1 and occludin [57]. In line are observations made at the airway epithelial after adenovirus infection. The decrease in TEER and rise in permeability of inulin, mannitol, and dextran was dependent on the functionality of the AJ protein E-cadherin [58]. Of note, enteroviruses have also been shown to take advantage of intercellular junctions to infect the CNS sometimes leading to alteration in protein expression $[53,59]$.

In response to viral entry into the CNS leukocytes migrate to the site of infection. To cross the protective barriers of the brain, leukocytes have the possibility to migrate either via the para- or transcellular route. Across endothelium, there are opposing views concerning the decisive factors for the choice of the mode of diapedesis, namely, trans- versus paracellular. On the one hand, it has been proposed in in vitro studies applying primary rat endothelial cells from the heart and brain and human lung and human microvascular endothelial cell lines that the path of least resistance is chosen by migrating 


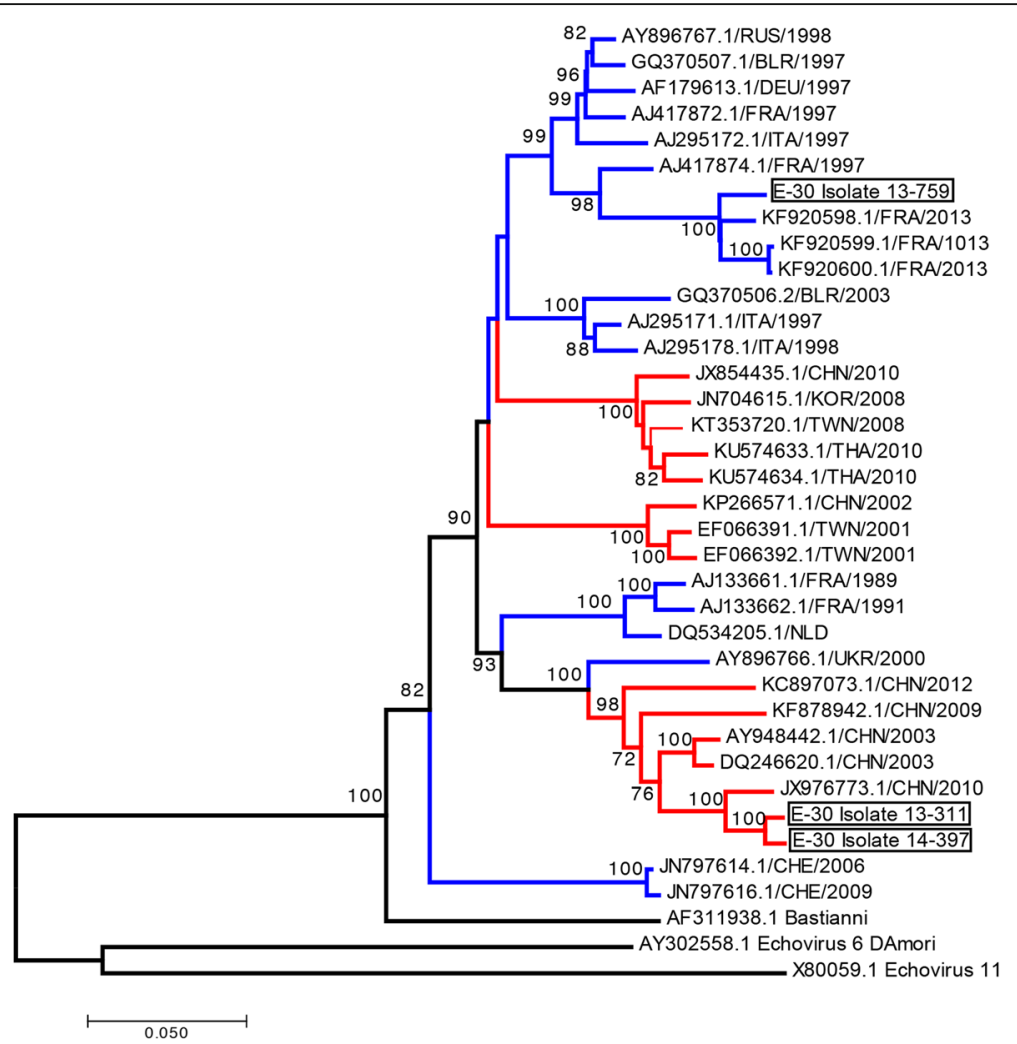

Fig. 10 Genetic sequence alignment of E-30 structural proteins VP1-4. Phylogenetic analysis of echovirus strains based on nucleotide regions encoding for full capsid proteins using representative strains from the GenBank database. Branch colors mark isolation location (Europe, blue; Asia, red). The strains identified in this work are indicated by black rectangles. Only bootstrap values $>70 \%$ are shown at relevant nodes. Sequences of prototypes strains of Echovirus11 (X80059.1) and Echovirus 6 (AY3025588.1) were used as an outgroup. Branch length is drawn to the indicated scale (number of nucleotide substitutions per site)

leukocytes [60]. Conversely, in more recent studies applying different BBB models the barrier integrity was not decisive for the preferred pathway and rapid remodeling of $\mathrm{TJ}$ even in very tight endothelium was observed during paracellular transmigration $[37,61$, 62]. Noteworthy, the involvement of chemokine and integrin activation can influence the pathway of leukocytes migration $[60,63]$, and we have recently shown, that infection of HIBCPP cells with E-30 Bastianni increased the migration of naive T-cells and PMN [23]. We hypothesized that infection with E-30 Bastianni and subsequent barrier impairment, including increased paracellular permeability, leads to a predominance of paracellular leukocyte migration. To verify this hypothesis, E-30 Bastianni was used, due to its most prominent effects on the barrier function and morphology of TJ and AJ. We could show in immunofluorescence studies as well as in TEM and FIB/ SEM analysis that PMN and T-cells use both modes of diapedeses across HIBCPP cells. This paralleled our previous observations that PMN use both pathways after bacterial infection of HIBCPP cells with Neisseria meningitidis [39].
Most evidence in the literature for PMN transmigration pointed towards a preference of the paracellular route [64, 65]. Still, after bacterial infection of PCPEC electron microscopic imaging revealed mainly transcellular migration [38], whereas in HICBPP both pathways are used [39]. Both in vivo and in vitro it was also demonstrated at the BBB that the level of endothelial ICAM seems crucial for the pathway of diapedesis and that for T-cells, the transcellular mode of diapedesis was more common [14, 37, 66]. The current study did not analyze the role of ICAM in the regulation of transmigration, since, ICAM is apically expressed on HIBCPP cells (unpublished data), so that leukocytes primarily do not interact with this integrin ligand at first contact. Thus, its role in our model should not be critical. Interestingly, primary $\mathrm{CD}^{+}{ }^{+}$T-cells were detected to only use the paracellular transendothelial route in vitro under flow conditions [67].

Evidence exists that barrier disruption is not a direct effect of viral infection of the CNS, but rather caused by a secondary effect such as virus replication within the brain [62]. In this context, we were able to show strainspecific growth patterns in HIBCPP cells. In this model, 
all three outbreak strains presented comparable percentages of infected cells, in contrast to E-30 Bastianni, which infected significantly more HIBCPP cells. Therefore, the similar effect on barrier function by strains E-30 Bastianni and 13-311 (functional and morphological impairment), and strains 13-759 and 14-397 (no observed effect), respectively, is most likely not related to viral replication levels or infection efficacy. Furthermore, the experiments on the localization of the viral genome copies within different compartments of the system indicated a faster infection frequency of E-30 Bastianni. In contrast, strain 13311 was comparable to strain 13-759 in this aspect.

To carry out cell-line comparison studies, RD cells were used because they are highly sensitive to E30 and other enterovirus strains. No significant strain-specific difference in replication in RD cells has been observed for the three outbreak strains. We therefore concluded that the replication pattern of the different outbreak strains cannot completely account for the differences on HIBCPP TJ and AJ function and morphology.

In order to investigate the possible determinants of the variant-specific differences in growth and effects on HIBCPP cell barrier function and morphology, sequence analysis of the viral strains was carried out. The capsid of infectious E-30 virions consist of four structural proteins, VP1-VP4, out of which only VP1- VP3 are in part exposed on the surface of the capsid. The VP1 protein has highly variable solvent exposed regions that define the antigenic characteristics of the serotype [11]. Important and frequent genetic recombination enhances sporadic seasonal outbreaks and extensive epidemics worldwide [68-71]. Most noteworthy are the genetic mutations in the VP1 region of E-30, which have been associated with meningitis causing outbreak serotypes $[11,72,73]$. Even the slightest changes in the amino acid sequence can influence the affinity of a virus for a particular receptor [74]. For example, a variant-specific effect on epithelial cells was proposed to be due to minor variations in the amino acid sequence in the P1 region of clinical CV-B isolates [75], and replacing a single amino acid in a CV-B variant confers the ability to infect RD cells [76]. Similar results were obtained by Smura et al. who first investigated strain-specific tropism and went on to show that a single amino acid replacement in the VP1 region of CV-B6-Schmitt strain may lead to enhanced replication and caused the non-lytic to lytic phenotypic switch [77]. Several clusters of increased frequency of amino acid variations have been identified, but so far not directly linked to the observed differences in the strains. Instead, we report a panel of amino acid substitutions that occurred in regions encoding both structural and non-structural proteins. Although so far, none of the mutations has been directly correlated with the observed effects, it would be possible that multiple genetic factors were involved in the phenotypic consequences. Intriguingly, despite the different cellular effects in vitro, polyproteins of the more virulent 13-311 and the less virulent 14-397 strain differed in only 10 amino acids. Moreover, phylogeny revealed global circulation of these E-30 variants. The strains 13-311 and 14397 seem closely related viruses. Software analysis of recombination did not suggest that 13-759 could be a recombinant form. Further experimental studies with sitedirected mutagenesis of infectious clones are needed to determine how these specific amino acid changes contribute to the pathogenic features and widespread of the virus.

\section{Conclusion}

We were able to show E-30 strain-specific effects on the integrity of the BCSFB in vitro. Particular 13-311 stood out, which, despite its many similarities to the other outbreak strains in relation to replication, viral dissemination or paracellular permeability, was the only one, which had similar effects on the TJ proteins of the BCSFB model as the prototype strain E-30 Bastianni. Despite the partial loss of junctional integrity induced by E-30 Bastianni, the migration of PMN and T-cells occurred both para- and transcellularly across the HIBCPP cells. The full genome sequencing highlighted genetic differences, which could, however, not be attributed to the experimentally observed differences. The study contributes to the understanding of the impact of different circulating E-30 genotypes on the level of the BCSFB. Still, for translation into the clinics, a correlation with prospectively assessed patient data is necessary. Consequently, a combination of functional in vitro and in vivo data (virulence, host cell response, and strain-specificity) and clinical data from patients, gathered during enteroviral outbreaks, could lead to a deeper understanding of enteroviral pathogenesis.

\section{Additional files}

Additional file 1: Measurement of HIBCPP cell viability after infection with E-30 with the Live/Dead and lactate dehydrogenase (LDH) assay. (A) Live/dead assay on HIBCPP cells after $28 \mathrm{~h}$ of infection with E-30 Bastianni, 13-311, 13-759, and 14-397. Representative images of four independent experiments each performed in triplicates are shown. (B) LDH activity assay on HIBCPP cells after $28 \mathrm{~h}$ of infection. $\mathrm{LDH}$-release into the supernatant by HIBCPP cells was measured after $28 \mathrm{~h}$ of infection with different echovirus strains. Data are shown as mean + SD of four independent experiments each performed in triplicates. Technical triplicates were used during the analytical evaluation. (TIFF 1907 kb)

Additional file 2: Paracellular PMN migration across HIBCPP in FIB/SEMraw data. FIB/SEM serial sections of paracellular polymorphonuclear neutrophil (PMN) migration through HIBCPP cells. Shows raw data SEM images from the condition HIBCPP+PMN + T-cells+E-30 + IL8. The video shows a paracellular migrating PMN presented in Fig. $8 \mathrm{a}, \mathrm{b}$ in orthoslices. (AVI $12267 \mathrm{~kb}$ ).

Additional file 3: Paracellular PMN migration across HIBCPP in FIB/SEMinverted images. FIB/SEM serial sections of paracellular 
polymorphonuclear neutrophil (PMN) migration through HIBCPP cells. Shows inverted SEM images from the condition HIBCPP+PMN + T-cells+E$30+$ IL8. The video shows a paracellular migrating PMN presented in Fig. 8a, b in orthoslices. (AVI $12638 \mathrm{~kb}$ )

Additional file 4: Paracellular PMN migration across HIBCPP in FIB/SEM3D slices. FIB/SEM serial sections of paracellular polymorphonuclear neutrophil (PMN) migration through HIBCPP cells. Shows SEM images taken from the condition HIBCPP+PMN + T-cells+E-30 + IL8, visualized as a three-dimensional volume and sliced along the $x$ - and $z$-axis. The video shows a paracellular migrating PMN presented in Fig. $8 \mathrm{a}, \mathrm{b}$ in orthoslices. (AVl $15748 \mathrm{~kb}$ )

Additional file 5: Paracellular PMN migration across HIBCPP in FIB/SEMNLM projection. FIB/SEM serial sections of paracellular polymorphonuclear neutrophil (PMN) migration through HIBCPP cells. Shows SEM images from the condition HIBCPP+PMN + T-cells+E- $30+I L 8$, visualized as a three-dimensional volume at different projections. The video shows a paracellular migrating PMN presented in Fig. 8a, b in orthoslices. (AVI $19100 \mathrm{~kb}$ )

Additional file 6: Transcellular T-cell migration across HIBCPP in FIB/ SEM-raw data. FIB/SEM serial sections of transcellular T-cell migration through HIBCPP cells. Shows raw data SEM images from the condition HIBCPP + PMN + T-cells+E-30 + CXCL12. The video shows a transcellular migrating T-cell presented in Fig. 8c, d in orthoslices. (AVI $8145 \mathrm{~kb}$ )

Additional file 7: Transcellular T-cell migration across HIBCPP in FIB/ SEM-inverted images FIB/SEM serial sections of transcellular T-cell migration through HIBCPP cells. Shows inverted SEM images from the condition HIBCPP+PMN + T-cells+E-30 + CXCL12. The video shows a transcellular migrating T-cell presented in Fig. $8 c$, d in orthoslices. (AVI $12000 \mathrm{~kb}$ )

Additional file 8: Transcellular T-cell migration across HIBCPP in FIB/ SEM-NLMG projection. FIB/SEM serial sections of transcellular T-cell migration through HIBCPP cells. Shows SEM images from the condition HIBCPP+PMN + T-cells+E-30 + CXCL12, visualized as a three-dimensional volume at different projections. The video shows a transcellular migrating T-cell presented in Fig. 8c, d in orthoslices. (AVI $11252 \mathrm{~kb}$ )

Additional file 9: Despite longer incubation periods, 13-759 and 14-397 do not show an impact on barrier integrity. Barrier integrity of HIBCPP cells was evaluated via measurement of the transepithelial electrical resistance (TEER) (A) at indicated time points after infection with E-30 Bastianni, 13-311, 13-759, or 14-397. TEER values at the start of the experiment (white bars), after $24 \mathrm{~h}$ (light gray) and after $48 \mathrm{~h}$ (dark gray) are shown.Data are shown as mean +SD of 2 independent experiments carried out in quadruples (B) Live/dead assay on HIBCPP cells after $48 \mathrm{~h}$ of infection with E-30 Bastianni, 13-311, 13-759, and 14-397. Representative images of two independent experiments each performed in triplicates are shown (C) HIBCPP cells were infected with E-30 Bastianni, 13311, 13-759, and 14-397 for $48 \mathrm{~h}$ and ZO1 staining was compared; cell layers were stained for nuclei with DAPI (shown here in blue), VP1 (shown here in green), and ZO-1 (red). For detailed description of image acquisition and preparation, please refer to Fig. 2. Two images per strain showing different grouping of parallel staining are displayed horizontally (column one: only ZO-1; column two: DAPI, VP-1, and ZO-1; E-30 strains are listed vertically. The images shown are representative examples of multiple stainings taken from two independent experiments each performed in duplicates. (TIFF $13334 \mathrm{~kb}$ )

Additional file 10: Verification of virulence after E-30 passage across the HIBCPP cells. HIBCPP cells were infected with E-30 Bastianni, 13-311, 13759, and 14-397 for 24 and $48 \mathrm{~h}$. (A) Shows the viral genome copies (shown in copies $/ \mathrm{ml}$ ) harvested after 24 or $48 \mathrm{~h}$ from the lower compartment (apical cell side). A schematic representation of the experimental setup indicates the experimental procedure. The undiluted supernatant was added to confluent RD monolayers, and the cytopathic effect was observed over 24 (B) and $48 \mathrm{~h}$ (C). Virulence was confirmed through the $\mathrm{RD}$ cells detaching from the well, rounding off and finally lysing. All viral strains show to have a cytopathic effect on RD cells. The images are representative frames from 2 experiments. (TIFF $9646 \mathrm{~kb}$ )

Additional file 11: $\mathrm{E}-30$ sequence alignments. Positions identical to those of Bastianni are indicated as dots. (A) Amino acid alignment of the
P1 region. The VP4, VP3, VP2, and VP1 protein sequences are shown in red, green, blue, and purple, respectively. (B) Amino acid alignment of the $\mathrm{P} 2$ region. The protein $2 \mathrm{C}, 2 \mathrm{~B}$, and $2 \mathrm{~A}$ sequences are shown in raspberry, orange, and light blue, respectively. (C) Amino acid alignment of the $\mathrm{P} 3$ region. The $3 \mathrm{C}$ protease, $\mathrm{VPg}$, and RNA-dependent RNA polymerase sequences are shown in green, purple, and red, respectively. (D) Nucleotide alignment of $5^{\prime} U T R$ regions. (E) Nucleotide alignment of $3^{\prime} U T R$ regions. (PDF $3120 \mathrm{~kb}$ )

Additional file 12: Amino acid substitutions observed between E-30 Bast. and the outbreak strains. To illustrate differences in between the E30 strains used, a table was designed with the data that has already been displayed in Additional file 11. The positions that matched between 13311 and the other three E-30 strains are highlighted in green; those that were different are left blank (white). 13-311 and 14-397 vary in 10 amino acids, whereas 13-311 and 13-759 vary in 70 amino acids. (PDF $139 \mathrm{~kb}$ )

\section{Abbreviations}

AJ: Adherens junction; BBB: Blood-brain barrier; BCSFB: Blood-cerebrospinal fluid barrier; BSA: Bovin serum albumin; CNS: Central nervous system; CSF: Cerebrospinal fluid; CV-B: Coxsackievirus B, family Picornaviridae, genus Enterovirus, species Human enterovirus B; E: Echovirus, family Picornaviridae, DAPI, 4'-6-diamidino-2-phenylindole dihydrochloride; FCS: Fetal calf serum, genus Enterovirus, species Human enterovirus B; FIB: Focused ion beam; HBMEC: Human brain microvascular endothelial cells; HIBCPP: Human choroid plexus papilloma cells; Hr: Hour; HRP: Horseradish peroxide; LDH: Lactate dehydrogenase; MAM: Migration assay medium; MOI: Multiplicity of infection; NPEV: Non-polio enterovirus; NRC PE: National Reference Centre for Poliomyelitis and Enteroviruses; Nt: Nucleotide; PCPEC: Primary porcine choroid plexus epithelial; PCR: Polymerase chain reaction; PMN: Polymorphonuclear neutrophil; qPCR: Quantitative real-time polymerase chain reaction; RD: Human rhabdomyosarcoma cells; RIPA: Radioimmunoprecipitation assay; RT: Room temperature; SD: Standard deviation; SEM: Scanning electron microscopy; TEER: Transepithelial electrical resistance; TEM: Transmission electron microscopy; TJ: Tight junction; VP1: Viral protein 1; ZO: Zonula occludens

\section{Acknowledgements}

Special thanks are due to Dr. rer. nat. Julia Borkowski and Dr. rer. nat. Martin März for their constructive comments on the paper.

\section{Funding}

HR was partly supported by the fellowship "Olympia Morata" from the Heidelberg University, Germany. We acknowledge financial support by Deutsche Forschungsgemeinschaft and Ruprecht-Karls-Universität Heidelberg within the funding programme Open Access Publishing.

\section{Availability of data and materials}

All data generated or analyzed during this study are included in this published article [and its supplementary information files].

\section{Authors' contributions}

$T D, T$, and HR conceived and coordinated the study, and drafted the manuscript. TD and HR performed the underlying experiments. OA performed the quantification of viral copies via qPCR. SB and SD provide the outbreak strains, monitored the experiments with the outbreak strains, and contributed to the genome sequencing and the phylogenetic analysis. VM and GH performed, analyzed, and interpreted the genome sequencing and the phylogenetic analysis. CW performed the statistics. HI and C S-G contributed to establish appropriate cell culture conditions. CS and HS both drafted the manuscript. P F-B, SS, and CB performed the electron microscopic studies. All authors have read and approved the final version of this manuscript

\section{Ethics approval and consent to participate}

Ethical approval for blood donations of voluntary healthy donors was obtained by the local ethics committee of the Medical Faculty of Mannheim, Heidelberg University (2009-327N-MA).

\section{Consent for publication} Not applicable 


\section{Competing interests}

The authors declare that they have no competing interests.

\section{Publisher's Note}

Springer Nature remains neutral with regard to jurisdictional claims in published maps and institutional affiliations.

\section{Author details}

'Pediatric Infectious Diseases, University Children's Hospital Mannheim, Medical Faculty Mannheim, Heidelberg University, Mannheim, Germany. ${ }^{2}$ Institute of Virology, University Hospital, Heinrich-Heine-University, Düsseldorf, Germany. ${ }^{3}$ National Reference Centre for Poliomyelitis and Enteroviruses, Robert Koch-Institute, Berlin, Germany. ${ }^{4}$ Schaller Research Group, University of Heidelberg and the DKFZ, Heidelberg, Germany. ${ }^{5}$ Department of Infectious Diseases, Virology, University of Heidelberg, Heidelberg, Germany. ${ }^{6}$ Institute of Pathology and Neuropathology, University Hospital of Tübingen, Tübingen, Germany. ${ }^{7}$ Carl Zeiss Microscopy $\mathrm{GmbH}$, ZEISS Group, Oberkochen, Germany. ${ }^{8} \mathrm{NMI}$ Natural and Medical Sciences Institute, University of Tübingen, Reutlingen, Germany. ${ }^{9}$ Institute of Medical Statistics and Biomathematics, Medical Faculty Mannheim, Heidelberg University, Mannheim, Germany. ${ }^{10}$ Department of NDU Life Sciences, School of life Dentistry, The Nippon Dental University, Tokyo, Japan.

\section{Received: 2 May 2017 Accepted: 9 January 2018}

\section{Published online: 20 February 2018}

\section{References}

1. Michos AG, Syriopoulou VP, Hadjichristodoulou C, Daikos GL, Lagona E, Douridas P, Mostrou G, Theodoridou M. Aseptic meningitis in children: analysis of 506 cases. PLoS One. 2007;2:e674.

2. Rudolph $\mathrm{H}$, Schroten $\mathrm{H}$, Tenenbaum T: Enterovirus infections of the central nervous system in children: an update. Pediatr Infect Dis J 2016, 35:567-569.

3. Nahdi I, Boukoum H, Nabil Ben Salem A, Ben Romdane F, Hammami S, Chebel S, Mahbouba FA, Guediche MN, Chakroun M, Aouni M, et al. Detection of herpes simplex virus ( 1 and 2), varicella-zoster virus, cytomegalovirus, human herpesvirus 6 and enterovirus in immunocompetent Tunisian patients with acute neuromeningeal disorder. J Med Virol. 2012;84:282-9.

4. Bastos MS, Lessa N, Naveca FG, Monte RL, Braga WS, Figueiredo LT, Ramasawmy R, Mourao MP. Detection of herpesvirus, enterovirus, and arbovirus infection in patients with suspected central nervous system viral infection in the western Brazilian Amazon. J Med Virol. 2014;86:1522-7.

5. Hu Y, Jiang L, Peng HL. Clinical analysis of 134 children with nervous system damage caused by enterovirus 71 infection. Pediatr Infect Dis J. 2015;34:718-23.

6. Pons-Salort M, Parker EP, Grassly NC. The epidemiology of non-polio enteroviruses: recent advances and outstanding questions. Curr Opin Infect Dis. 2015;28:479-87.

7. Li W, Qiong Z, Xiao-Ting S, Yu-Jie L, Jian-Hua M, Qiang S, Shi-Qiang S. Molecular epidemiological study of enteroviruses associated with encephalitis in children from Hangzhou, China. Medicine (Baltimore). 2016;95:e4870.

8. Roth B, Enders M, Arents A, Pfitzner A, Terletskaia-Ladwig E. Epidemiologic aspects and laboratory features of enterovirus infections in Western Germany, 2000-2005. J Med Virol. 2007;79:956-62.

9. Richter J, Koptides D, Tryfonos C, Christodoulou C. Colecular typing of enteroviruses associated with viral meningitis in Cyprus, 2000-2002. J Med Microbiol. 2006;55:1035-41.

10. Tryfonos C, Richter J, Koptides D, Yiangou M, Christodoulou CG. Molecular typing and epidemiology of enteroviruses in Cyprus, 2003-2007. J Med Microbiol. 2011;60:1433-40.

11. Xiao H, Guan D, Chen R, Chen P, Monagin C, Li W, Su J, Ma C, Zhang W, Ke C. Molecular characterization of echovirus 30-associated outbreak of aseptic meningitis in Guangdong in 2012. Virol J. 2013;10:263.

12. Pinto Junior VL, Rebelo MC, Costa EV, Silva EE, Boia MN. Description of a widespread outbreak of aseptic meningitis due to echovirus 30 in Rio de Janeiro state, Brazil. Braz J Infect Dis. 2009;13:367-70.

13. Dahm T, Rudolph H, Schwerk C, Schroten H, Tenenbaum T. Neuroinvasion and inflammation in viral central nervous system infections. Mediat Inflamm. 2016;2016:8562805.

14. Engelhardt B, Wolburg-Buchholz K, Wolburg H. Involvement of the choroid plexus in central nervous system inflammation. Microsc Res Tech. 2001;52:112-29.
15. Bozym RA, Morosky SA, Kim KS, Cherry S, Coyne CB. Release of intracellular calcium stores facilitates coxsackievirus entry into polarized endothelial cells. PLoS Pathog. 2010;6:e1001135.

16. Coyne CB, Kim KS, Bergelson JM. Poliovirus entry into human brain microvascular cells requires receptor-induced activation of SHP-2. EMBO J. 2007;26:4016-28.

17. Volle R, Archimbaud C, Couraud PO, Romero IA, Weksler B, Mirand A, Pereira $B$, Henquell C, Peigue-Lafeuille $H$, Bailly JL. Differential permissivity of human cerebrovascular endothelial cells to enterovirus infection and specificities of serotype EV-A71 in crossing an in vitro model of the human blood-brain barrier. J Gen Virol. 2015;96:1682-95.

18. Tabor-Godwin JM, Ruller CM, Bagalso N, An N, Pagarigan RR, Harkins S, Gilbert PE, Kiosses WB, Gude NA, Cornell CT, et al. A novel population of myeloid cells responding to coxsackievirus infection assists in the dissemination of virus within the neonatal CNS. J Neurosci. 2010;30:8676-91.

19. Schneider H, Weber CE, Schoeller J, Steinmann U, Borkowski J, Ishikawa H, Findeisen P, Adams O, Doerries R, Schwerk C, et al. Chemotaxis of T-cells after infection of human choroid plexus papilloma cells with echovirus 30 in an in vitro model of the blood-cerebrospinal fluid barrier. Virus Res. 2012;170:66-74.

20. Muehlenbachs A, Bhatnagar J, Zaki SR. Tissue tropism, pathology and pathogenesis of enterovirus infection. J Pathol. 2015;235:217-28.

21. Engelhardt B, Ransohoff RM. Capture, crawl, cross: the T cell code to breach the blood-brain barriers. Trends Immunol. 2012;33:579-89.

22. Tietz S, Engelhardt B. Brain barriers: crosstalk between complex tight junctions and adherens junctions. J Cell Biol. 2015;209:493-506.

23. Dahm T, Frank F, Adams O, Lindner HA, Ishikawa H, Weiss C, Schwerk C, Schroten $\mathrm{H}$, Tenenbaum T, Rudolph $\mathrm{H}$. Sequential transmigration of polymorphonuclear cells and naive CD3+ T lymphocytes across the bloodcerebrospinal-fluid barrier in vitro following infection with echovirus 30 . Virus Res. 2017;232:54-62.

24. Fukushima K, Ishiguro A, Shimbo T. Transient elevation of granulocyte colony-stimulating factor levels in cerebrospinal fluid at the initial stage of aseptic meningitis in children. Pediatr Res. 1995;37:160-4.

25. Romero JR. Diagnosis and management of enteroviral Infections of the central nervous system. Curr Infect Dis Rep. 2002;4:309-16.

26. Sato M, Hosoya M, Honzumi K, Watanabe M, Ninomiya N, Shigeta S, Suzuki H. Cytokine and cellular inflammatory sequence in enteroviral meningitis. Pediatrics. 2003;112:1103-7.

27. Rotbart HA. Viral meningitis. Semin Neurol. 2000;20:277-92.

28. Lucht F, Cordier G, Pozzetto B, Fresard A, Revillard JP. Evidence for T-cell involvement during the acute phase of echovirus meningitis. J Med Virol. 1992:38:92-6.

29. Wittchen ES. Endothelial signaling in paracellular and transcellular leukocyte transmigration. Front Biosci (Landmark Ed). 2009;14:2522-45.

30. Chin AC, Parkos CA. Pathobiology of neutrophil transepithelial migration: implications in mediating epithelial injury. Annu Rev Pathol. 2007;2:111-43.

31. Muller WA. Mechanisms of leukocyte transendothelial migration. Annu Rev Pathol. 2011;6:323-44.

32. Engelhardt $\mathrm{B}$, Wolburg H. Mini-review: Transendothelial migration of leukocytes: through the front door or around the side of the house? Eur J Immunol. 2004;34:2955-63.

33. Filippi MD. Mechanism of diapedesis: importance of the transcellular route. Adv Immunol. 2016;129:25-53.

34. Ransohoff RM, Kivisakk P, Kidd G. Three or more routes for leukocyte migration into the central nervous system. Nat Rev Immunol. 2003;3:569-81.

35. Nash S, Stafford J, Madara JL. Effects of polymorphonuclear leukocyte transmigration on the barrier function of cultured intestinal epithelial monolayers. J Clin Invest. 1987;80:1104-13.

36. Brazil JC, Parkos CA. Pathobiology of neutrophil-epithelial interactions. Immunol Rev. 2016;273:94-111.

37. Abadier M, Haghayegh Jahromi N, Cardoso Alves L, Boscacci R, Vestweber D, Barnum S, Deutsch U, Engelhardt B, Lyck R. Cell surface levels of endothelial ICAM-1 influence the transcellular or paracellular T-cell diapedesis across the blood-brain barrier. Eur J Immunol. 2015;45:1043-58

38. Wewer C, Seibt A, Wolburg H, Greune L, Schmidt MA, Berger J, Galla HJ, Quitsch U, Schwerk C, Schroten H, Tenenbaum T. Transcellular migration of neutrophil granulocytes through the blood-cerebrospinal fluid barrier after infection with Streptococcus suis. J Neuroinflammation. 2011;8:51.

39. Steinmann U, Borkowski J, Wolburg H, Schroppel B, Findeisen P, Weiss C, Ishikawa H, Schwerk C, Schroten H, Tenenbaum T. Transmigration of polymorphnuclear neutrophils and monocytes through the human blood- 
cerebrospinal fluid barrier after bacterial infection in vitro. J Neuroinflammation. 2013;10:31.

40. Ishiwata I, Ishiwata C, Ishiwata E, Sato Y, Kiguchi K, Tachibana T, Hashimoto $\mathrm{H}$, Ishikawa $\mathrm{H}$. Establishment and characterization of a human malignant choroids plexus papilloma cell line (HIBCPP). Hum Cell. 2005;18:67-72.

41. Dinner S, Kaltschmidt J, Stump-Guthier C, Hetjens S, Ishikawa H, Tenenbaum T, Schroten H, Schwerk C. Mitogen-activated protein kinases are required for effective infection of human choroid plexus epithelial cells by Listeria monocytogenes. Microbes Infect. 2017;19:18-33.

42. Schwerk C, Papandreou T, Schuhmann D, Nickol L, Borkowski J, Steinmann U, Quednau N, Stump C, Weiss C, Berger J, et al. Polar invasion and translocation of Neisseria meningitidis and Streptococcus suis in a novel human model of the blood-cerebrospinal fluid barrier. PLoS One. 2012;7:e30069.

43. Plager $\mathrm{H}$, Decher W. A newly-recognized enterovirus isolated from cases of aseptic meningitis. Am J Hyg. 1963;77:26-8.

44. Tenenbaum T, Papandreou T, Gellrich D, Friedrichs U, Seibt A, Adam R, Wewer C, Galla HJ, Schwerk C, Schroten H. Polar bacterial invasion and translocation of Streptococcus Suis across the blood-cerebrospinal fluid barrier in vitro. Cell Microbiol. 2009;11:323-36.

45. Knott G, Rosset S, Cantoni M. Focussed ion beam milling and scanning electron microscopy of brain tissue. J Vis Exp. 2011;(53):e2588. https://doi. org/10.3791/2588.

46. Villinger C, Gregorius H, Kranz C, Hohn K, Munzberg C, von Wichert G, Mizaikoff B, Wanner G, Walther P. FIB/SEM tomography with TEM-like resolution for 3D imaging of high-pressure frozen cells. Histochem Cell Biol. 2012;138:549-56.

47. Dragonfly 2.0 [Computer software]. Object Research Systems (ORS) Inc, Montreal, Canada, 2016; software available at http://www.theobjects.com/.

48. Torres-Flores JM, Arias CF. Tight junctions go viral. Viruses. 2015;7:5145-54.

49. Leitch ECM, Bendig J, Cabrerizo M, Cardosa J, Hyypia T, Ivanova OE, et al. Transmission Networks and Population Turnover of Echovirus 30. J Virol. 2009;83:2109-18.

50. Bailly JL, Mirand A, Henquell C, Archimbaud C, Chambon M, Charbonne F, Traore O, Peigue-Lafeuille H. Phylogeography of circulating populations of human echovirus 30 over 50 years: nucleotide polymorphism and signature of purifying selection in the VP1 capsid protein gene. Infect Genet Evol. 2009:9:699-708.

51. Oberste MS, Maher K, Kennett ML, Campbell JJ, Carpenter MS, Schnurr D, Pallansch MA. Molecular epidemiology and genetic diversity of echovirus type 30 (E30): genotypes correlate with temporal dynamics of E30 isolation. J Clin Microbiol. 1999;37:3928-33.

52. Kivisakk P, Mahad DJ, Callahan MK, Trebst C, Tucky B, Wei T, Wu L, Baekkevold ES, Lassmann H, Staugaitis SM, et al. Human cerebrospinal fluid central memory CD4+ T cells: evidence for trafficking through choroid plexus and meninges via P-selectin. Proc Natl Acad Sci U S A. 2003;100: 8389-94.

53. Haseloff RF, Dithmer S, Winkler L, Wolburg H, Blasig IE. Transmembrane proteins of the tight junctions at the blood-brain barrier: structural and functional aspects. Semin Cell Dev Biol. 2015;38:16-25.

54. Coyne CB, Bergelson JM. Virus-induced Abl and Fyn kinase signals permit coxsackievirus entry through epithelial tight junctions. Cell. 2006;124:119-31.

55. Bleau C, Filliol A, Samson M, Lamontagne L. Brain invasion by mouse hepatitis virus depends on impairment of tight junctions and beta interferon production in brain microvascular endothelial cells. J Virol. 2015; 89:9896-908.

56. Mateo M, Generous A, Sinn PL, Cattaneo R. Connections matter-how viruses use cell-cell adhesion components. J Cell Sci. 2015;128:431-9.

57. Tan S, Duan H, Xun T, Ci W, Qiu J, Yu F, Zhao X, Wu L, Li L, Lu L, et al. HIV-1 impairs human retinal pigment epithelial barrier function: possible association with the pathogenesis of HIV-associated retinopathy. Lab Investig. 2014;94:777-87.

58. Man Y, Hart VJ, Ring CJ, Sanjar S, West MR. Loss of epithelial integrity resulting from E-cadherin dysfunction predisposes airway epithelial cells to adenoviral infection. Am J Respir Cell Mol Biol. 2000;23:610-7.

59. Rhoades RE, Tabor-Godwin JM, Tsueng G, Feuer R. Enterovirus infections of the central nervous system. Virology. 2011;411:288-305.

60. Martinelli R, Zeiger AS, Whitfield M, Sciuto TE, Dvorak A, Van Vliet KJ, Greenwood J, Carman CV. Probing the biomechanical contribution of the endothelium to lymphocyte migration: diapedesis by the path of least resistance. J Cell Sci. 2014;127:3720-34.
61. Muller WA. Transendothelial migration: unifying principles from the endothelial perspective. Immunol Rev. 2016;273:61-75.

62. Winger RC, Koblinski JE, Muller WA. Pathway of leukocyte transendothelial migration across an in vitro human blood brain barrier model. J Immunol. 2014; 193(5):2427-37. https://doi.org/10.4049/jimmunol.1400700. Epub 2014 Jul 25.

63. Mamdouh Z, Mikhailov A, Muller WA. Transcellular migration of leukocytes is mediated by the endothelial lateral border recycling compartment. J Exp Med. 2009;206:2795-808.

64. Kolaczkowska E, Kubes P. Neutrophil recruitment and function in health and inflammation. Nat rev Immunol. Nat Rev Immunol. 2013;13:159-75.

65. Borregaard N. Neutrophils, from marrow to microbes. Immunity. 2010;33:657-70.

66. Rudolph H, Klopstein A, Gruber I, Blatti C, Lyck R, Engelhardt B. Postarrest stalling rather than crawling favors CD8(+) over CD4(+) T-cell migration across the blood-brain barrier under flow in vitro. Eur J Immunol. 2016;46:2187-203.

67. Yang L, Froio RM, Sciuto TE, Dvorak AM, Alon R, Luscinskas FW. ICAM-1 regulates neutrophil adhesion and transcellular migration of TNF-alphaactivated vascular endothelium under flow. Blood. 2005;106:584-92.

68. Lugo D, Krogstad P. Enteroviruses in the early 21 st century: new manifestations and challenges. Curr Opin Pediatr. 2016;28:107-13.

69. Casas N, Sunen E. Detection of enteroviruses, hepatitis a virus and rotaviruses in sewage by means of an immunomagnetic capture reverse transcription-PCR assay. Microbiol Res. 2002;157:169-75.

70. Palacios G, Casas I, Cisterna D, Trallero G, Tenorio A, Freire C. Molecular epidemiology of echovirus 30: temporal circulation and prevalence of single lineages. J Virol. 2002;76:4940-9.

71. Molet L, Saloum K, Marque-Juillet S, Garbarg-Chenon A, Henquell C, Schuffenecker I, Peigue-Lafeuille H, Rozenberg F, Mirand A. Enterovirus infections in hospitals of lle de France region over 2013. J Clin Virol. 2016;74:37-42.

72. Bailly JL, Brosson D, Archimbaud C, Chambon M, Henquell C, PeigueLafeuille $\mathrm{H}$. Genetic diversity of echovirus 30 during a meningitis outbreak, demonstrated by direct molecular typing from cerebrospinal fluid. J Med Virol. 2002;68:558-67.

73. Thoelen I, Lemey P, Van Der Donck I, Beuselinck K, Lindberg AM, Van Ranst $M$. Molecular typing and epidemiology of enteroviruses identified from an outbreak of aseptic meningitis in Belgium during the summer of 2000. J Med Virol. 2003;70:420-9.

74. Muckelbauer JK, Rossmann MG. The structure of coxsackievirus B3. Curr Top Microbiol Immunol. 1997;223:191-208.

75. Riabi S, Harrath R, Gaaloul I, Bouslama L, Nasri D, Aouni M, Pillet S, Pozzetto B. Study of Coxsackie B viruses interactions with Coxsackie adenovirus receptor and decay-accelerating factor using human $\mathrm{CaCo}-2$ cell line. J Biomed Sci. 2014;21:50.

76. Pan J, Narayanan B, Shah S, Yoder JD, Cifuente JO, Hafenstein S, Bergelson JM. Single amino acid changes in the virus capsid permit coxsackievirus B3 to bind decay-accelerating factor. J Virol. 2011;85:7436-43.

77. Smura T, Natri O, Ylipaasto P, Hellman M, Al-Hello H, Piemonti L, Roivainen $M$. Enterovirus strain and type-specific differences in growth kinetics and virus-induced cell destruction in human pancreatic duct epithelial HPDE cells. Virus Res. 2015;210:188-97.

\section{Submit your next manuscript to BioMed Central and we will help you at every step:}

- We accept pre-submission inquiries

- Our selector tool helps you to find the most relevant journal

- We provide round the clock customer support

- Convenient online submission

- Thorough peer review

- Inclusion in PubMed and all major indexing services

- Maximum visibility for your research

Submit your manuscript at www.biomedcentral.com/submit 